\title{
The reaction network in propane oxidation over phase-pure MoVTeNb M1 oxide catalysts
}

Raoul Naumann d'Alnoncourt ${ }^{1,2}$, Lénárd-István Csepei ${ }^{1}$, Michael Hävecker, Frank Girgsdies ${ }^{l}$, Manfred E. Schuster ${ }^{1}$, Robert Schlögl ${ }^{1}$, and Annette Trunschke $e^{1, *}$

${ }^{1}$ Department of Inorganic Chemistry, Fritz-Haber-Institut der Max-Planck-Gesellschaft, Faradayweg 4-6, 14195 Berlin, Germany.

${ }^{2}$ Present address: Technical University Berlin, BasCat - UniCat BASF Joint, LabVilla Bell, Marchstraße 6, 10587 Berlin, Germany.

${ }^{3}$ Department of Solar Energy Research, Helmholtz-Zentrum Berlin/BESSY II, Albert-EinsteinStr. 15, 12489 Berlin, Germany.

\footnotetext{
* Corresponding author, mailing address: Dr. Annette Trunschke, Department of Inorganic Chemistry, Fritz Haber Institute of the Max Planck Society, Faradayweg 4-6, D-14195 Berlin, Germany; Phone: +49-30-8413-4457; Fax: +49-30-8413-4405; E-mail: trunschke@fhi-berlin.mpg.de
} 


\section{Abstract}

MoVTeNb oxide catalysts exclusively composed of the M1 phase (ICSD no. 55097) have been studied in the direct oxidation of propane to acrylic acid applying a broad range of reaction conditions with respect to temperature (623-633-643-653-663 K), $\mathrm{O}_{2}$ concentration in the feed (4.5-6.0-9.0-12.0\%), steam concentration in the feed (0-10-20-40\%), and contact time (0.06-0.12-0.18-0.24-0.36-0.48-0.72-1.44 $\left.\mathrm{s} \mathrm{g}_{\text {cat }} \mathrm{Nml}^{-1}\right)$. The molar fraction of propane was kept at $3.0 \%$. Model experiments were performed to study the reactivity of possible intermediates propene, acrolein, and CO. The impact of auxiliary steam on the chemical nature of the catalyst surface was analyzed by in-situ photoelectron spectroscopy, while insitu X-ray diffraction has been carried out to explore the structural stability of the M1 phase under stoichiometric, oxidizing, and reducing reaction conditions. Phase purity apparently accomplishes absolute stability in terms of the crystalline bulk structure and the catalytic performance over month even under extreme reaction conditions. In contrast, the catalyst surface changes dynamically and reversibly when the feed composition is varied, but only in the outermost surface layer in a depth of around one nanometer. The addition of steam causes enrichment in $\mathrm{V}$ and Te on the surface at the expense of Mo. Surface vanadium becomes more oxidized in presence of steam. These changes correlate with the abundance of acrylic acid detected in the in-situ photoelectron spectroscopy experiment. Analysis of the threedimensional experimental parameter field measured in fixed bed reactors revealed that the complexity of the reaction network in propane oxidation over MoVTeNb oxide is reduced compared to less-defined catalysts due to phase purity and homogeneity. The oxidative dehydrogenation of propane to propene followed by allylic oxidation of propene comprises the main route to acrylic acid. The oxygen partial pressure was identified as an important process parameter that controls the activity in propane oxidation over phase-pure M1 without negative implications on the selectivity. High $\mathrm{O}_{2}$ concentration in the feed keeps the catalyst in a high oxidation state, which provides an increased number of active sites for propane activation. Auxiliary steam increases activity and selectivity of M1 by changing the chemical nature of the active sites and by facilitating acrylic acid desorption.

\section{Keywords}

Propane; Oxidation; Acrylic acid; Propene; Selectivity; Bulk; Surface; Reaction mechanism; Operando; Mixed oxide 
Graphical abstract

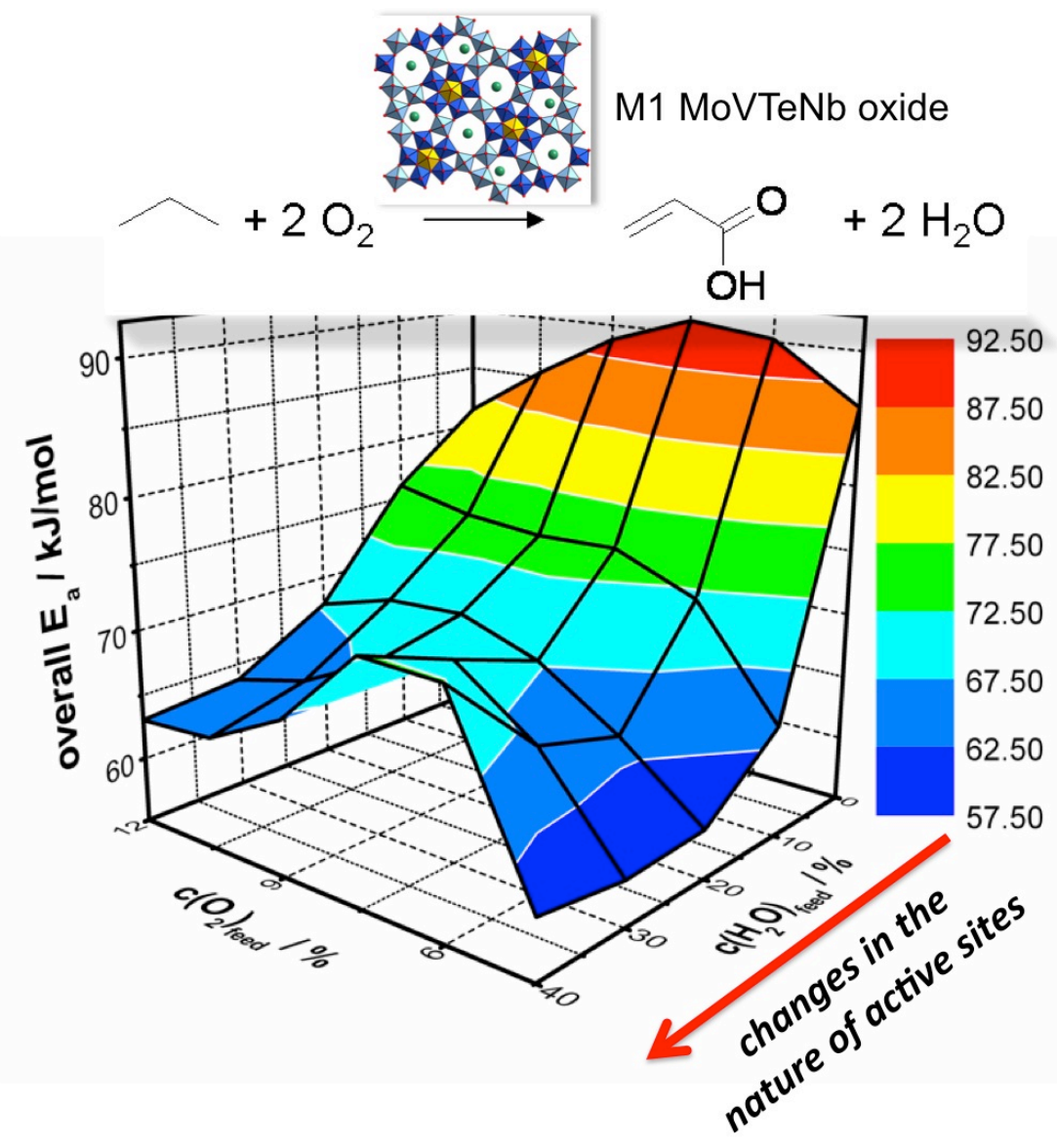




\section{Highlights}

- Phase purity and homogeneity ensure high stability of $\mathrm{MoVTeNbO}_{\mathrm{x}}$ in $\mathrm{C}_{3} \mathrm{H}_{8}$ oxidation

- The catalyst bears a self-supported active layer in sub-nanometer dimension

- Higher $\mathrm{O}_{2}$ content in the feed increases the activity without loss of selectivity

- Oxygen partial pressure affects surface oxidation state and number of active sites

- Auxiliary steam changes performance by modifying the nature of the active sites 


\section{Introduction}

Selectivity is the key challenge in oxidation of alkanes over heterogeneous catalysts. Excessive combustion of the substrate hampers so far broad application of direct oxidation processes in the chemical industry. The lack of control originates from the complexity of the underlying reaction networks that usually comprise multistep consecutive and parallel reactions.[1-13] The direct oxidation of propane to acrylic acid requires the transfer of eight electrons, the abstraction of four hydrogen atoms, and the addition of two oxygen atoms to the hydrocarbon skeletal without C-C bond splitting to obtain the desired final product. Hydrogen abstraction and oxygen addition demand substantially different functionalities of the catalyst with respect to the nucleophilicity of the involved oxygen species,[2, 14-16] implying desorption and re-adsorption of intermediates or proximity of different active sites on the catalyst surface. Revealing in particular the unselective pathways would clear the way for improvements in catalyst and process design.

In the present study, we deal with highly productive $\mathrm{MoVTeNb}$ mixed oxides as catalysts in direct oxidation of propane to acrylic acid. The corresponding reaction mechanism has been addressed in a number of kinetic studies. $[3,7,8,11,12,17,18]$ However, the shortcoming of some of these investigations consist in the ill-defined nature of the studied catalysts, which are often composed of a mixture of various crystalline and amorphous phases characterized by different chemical composition, surface termination, and, consequently, different active sites that may be responsible for additional consecutive and side reactions.[12, 19] Occasionally, it has been reported that the catalysts suffer from deactivation phenomena,[11] but, in most of the cases, no statements regarding catalyst stability have been made. In addition, the applied propane to oxygen ratios are very different ranging from reducing to strongly oxidizing feed, which makes it even more difficult to compare catalytic data of the individual studies. 
To overcome these drawbacks, we launched a campaign to study a well-defined, phase-pure, and highly crystalline MoVTeNb oxide catalyst exclusively composed of the so-called M1 crystal structure (ICSD no. 55097) in a broad field of reaction conditions in propane oxidation to acrylic acid. Surface chemistry and structural stability of the M1 catalyst under reaction conditions of propane oxidation are tackled by in-situ photoelectron spectroscopy and in-situ $\mathrm{XRD}$ experiments, respectively, and discussed in terms of the kinetic results in propane oxidation.

Unscrambling the propane oxidation network over MoVTeNb oxides into elementary steps is an ambitious and possibly unsolvable task due to the multitude of different and interrelated organic reactions happening on the catalyst surface and perhaps also in the gas phase. Therefore, instead of establishing a micro kinetic model, we pursue an alternative approach in the present work. According to this, general gradients in the three-dimensional data space obtained by broad variation of the operation conditions are identified. Trends in kinetic parameters acquired by this method provide experimental indication to distinguish between selective and non-selective pathways. Based on the results, selectivity limits in direct oxidation of propane to acrylic acid over MoVTeNb M1 oxide catalysts will be discussed.

\section{Materials and Methods}

\subsection{Catalyst preparation and characterization}

Five batches of crystalline MoVTeNb mixed oxide consisting exclusively of the crystal structure described in literature as M1 phase (ICSD no. 55097) were investigated (internal catalyst batch numbers $6059,6902,8612,8947$, and 10790). Three of these batches $(6059$, 8612, and 8947) stem from the same precursor material (precursor 6058), while the other two batches are complete reproductions of the whole synthesis process. A detailed description of the synthesis is given elsewhere.[20] In short, phase-pure M1 was prepared in three steps. The 
first step is adapted from a procedure described by Ushikubo et al.[21] It consists of coprecipitation, followed by aging within the mother liquor for 30 minutes, spray-drying of the resulting slurry and thermal treatments in flowing air $(548 \mathrm{~K})$ and argon $(873 \mathrm{~K})$. The product of the first step is a biphasic mixture of the MoVTeNb mixed oxide phases M1 and M2 (ICSD no. 55098). In the second step, M2 was removed from the biphasic mixture by a washing process using $\mathrm{H}_{2} \mathrm{O}_{2}$ solution.[22] In the third step, the catalyst precursor was activated by a thermal treatment at $873 \mathrm{~K}$ in flowing Ar.

The phase purity was confirmed by powder X-ray diffraction (XRD), using a Bruker D8 ADVANCE diffractometer equipped with $\mathrm{Cu} K \alpha_{1+2}$ radiation, a secondary graphite monochromator, and a scintillation counter. Analysis of XRD data were performed by Rietveld full patterns fitting using the software package Topas (v 4.2, Bruker AXS) and the M1 crystal structure model of DeSanto et al..[23] Mean crystallite sizes are calculated based on the double-Voigt approach and reported as $L_{\mathrm{Vol}} \mathrm{IB}$ values (volume weighted mean column length based on integral breadth) without further assumptions about crystallite shape or size distribution.[24]

The surface area measurement was carried out in a volumetric $\mathrm{N}_{2}$ physisorption set-up (Autosorb-6-B, Quantachrome) at the temperature of liquid nitrogen. The sample was degassed in dynamic vacuum at a temperature of $423 \mathrm{~K}$ for $2 \mathrm{~h}$ prior to physisorption. Full adsorption and desorption isotherms were measured. The linear part of the adsorption isotherm in the pressure range $\mathrm{p} / \mathrm{p}^{\circ}=0.05-0.3$ was considered to calculate the specific surface area according to the BET method.[25]

The chemical composition was analyzed by EDX applying a Hitachi S-4800 scanning electron microscope with an EDAX Genesis EDX detector. The measurements were carried out with an accelerating voltage of $10 \mathrm{kV}$. 


\subsection{In-situ Photoelectron spectroscopy}

In-situ X-ray photoelectron spectroscopy (XPS) has been performed at the synchrotron radiation facility BESSY II of the HZB (Helmholtz-Zentrum, Berlin) using monochromatic radiation of the ISISS (Innovative Station for In Situ Spectroscopy) beamline as a tuneable Xray source. High-pressure XPS spectra were obtained in the presence of reactive gases at elevated temperature using the high-pressure end station designed and constructed at the Fritz-Haber-Institut. Details of the set-up are described elsewhere.[26-29] The applied experimental procedure followed the one outlined previously.[30] In brief, $15 \mathrm{mg}$ of catalyst powder (batch 10790) was pressed to a disk and placed inside the XPS analysis cell with a volume of about $5 \mathrm{~L}$. Gases are introduced to the cell via calibrated mass flow controllers, heating is provided by a NIR laser $(808 \mathrm{~nm}, \mathrm{cw})$ at the rear of the sample, and the temperature is monitored by a thermocouple attached directly to the sample surface. Mixtures of $\mathrm{O}_{2} / \mathrm{C}_{3} \mathrm{H}_{8} / \mathrm{He}$ and $\mathrm{O}_{2} / \mathrm{C}_{3} \mathrm{H}_{8} / \mathrm{H}_{2} \mathrm{O}(\mathrm{g})$ with volume flows of $2 \mathrm{sccm} / 1 \mathrm{sccm} / 2.8 \mathrm{sccm}$ have been introduced resulting in a total pressure in the XPS chamber of $25 \mathrm{~Pa}$, and the heating rate was $5 \mathrm{~K} / \mathrm{min}$ up to the final temperature of $693 \mathrm{~K}$. The reaction products were analyzed by online proton transfer reaction mass spectrometry (PTR-MS, IONICON). Sets of core level spectra of $\mathrm{O} 1 \mathrm{~s}, \mathrm{~V} 2 \mathrm{p}, \mathrm{Mo} 3 \mathrm{~d}, \mathrm{Te} 3 \mathrm{~d}, \mathrm{Nb} 3 \mathrm{~d}$, and $\mathrm{C} 1 \mathrm{~s}$ have been obtained with a constant kinetic energy of the photoelectrons of $150 \mathrm{eV}$ and $750 \mathrm{eV}$, respectively, resulting in an inelastic mean free path (IMFP) of approximately $0.6 \mathrm{~nm}$ ("surface”) and $1.6 \mathrm{~nm}$ ("bulk"), respectively, calculated for $\mathrm{MoO}_{3}$ after Tanuma et al..[31] The binding energy (BE) scale was calibrated with respect to the valence band onset. $\mathrm{V} 2 \mathrm{p}^{3 / 2}$ peak deconvolution and quantitative element abundance calculations were performed using CASA data analysis software (Neil Farley, www.casaxps.com) evaluating normalized core level intensities after subtraction of a Shirley type background taking into account the photon energy dependence of the atomic subshell photo-ionization cross sections[32] and the incident photon flux. Element abundance values 
are given relative to the sum of metal content (i.e. sum of $\mathrm{Mo}, \mathrm{Te}, \mathrm{V}$, and $\mathrm{Nb}$ ) not considering oxygen and carbon.

\subsection{In-situ XRD experiments}

In-situ XRD data were collected on a STOE Theta/theta diffractometer $\left(\mathrm{Cu} \mathrm{K} \alpha_{1+2}\right.$ radiation, secondary graphite monochromator, scintillation counter) equipped with an Anton Paar XRK 900 in-situ reactor chamber. The gas feed was mixed by means of Bronkhorst mass flow controllers, using helium as inert balance gas. Steam was fed to the in-situ cell by saturation of a He carrier gas stream with water at a controlled temperature. A catalyst mass of $211 \mathrm{mg}$

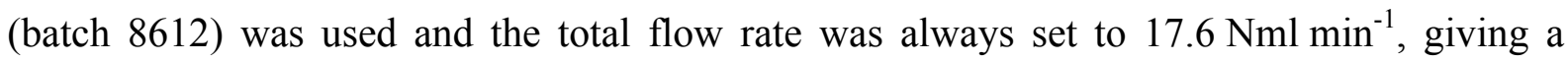
contact time of $0.72 \mathrm{~s} \mathrm{~g} \mathrm{Nml}^{-1}$. Thus, the experiments were carried out at a long contact time that gives high conversion of propane. The effluent gas composition was monitored with a Pfeiffer OmniStar quadrupole mass spectrometer.

The in-situ XRD experiment was carried out in a series of 12 steps (Table 1). Before and after the actual in-situ treatment (steps 1 and 12, respectively), diffraction patterns with longer counting times were recorded at $298 \mathrm{~K}$ in flowing He. In step 2, a single diffractogram was recorded at $673 \mathrm{~K}$ in flowing He, i.e., at reaction temperature. In steps $3-11$, various feed gas compositions were applied (Table 1), while the temperature was kept at $673 \mathrm{~K}$. Reducing, stoichiometric, and oxidizing reaction conditions were investigated, in presence or absence of steam. During this time, diffractograms were recorded continuously to check for occurrence of slow solid-state transformations. As no changes of the XRD patterns were detected during steps 3 -10, all diffractograms collected within a step were summed up to obtain a better signal/noise ratio for evaluation. At the end of step 11, the sample was cooled to $298 \mathrm{~K}$ before the feed gas was switched to He. The total time on stream at $673 \mathrm{~K}$ amounted to more than 16 days. 


\section{Table 1}

Experimental conditions during in-situ XRD experiments applying a contact time

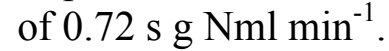

\begin{tabular}{lllllll}
\hline step & $\boldsymbol{T} / \mathbf{K}$ & $\boldsymbol{c}\left(\mathbf{C}_{\mathbf{3}} \mathbf{H}_{\mathbf{8}}\right) / \%$ & $\boldsymbol{c}\left(\mathbf{O}_{2}\right) / \%$ & $c\left(\mathbf{H}_{\mathbf{2}} \mathbf{O}\right) / \%$ & $c(\mathbf{H e}) / \%$ & Duration $^{\mathbf{1} / \mathbf{h}}$ \\
\hline $\mathbf{1}$ & 298 & 0 & 0 & 0 & 100 & 10 \\
$\mathbf{2}$ & 673 & 0 & 0 & 0 & 100 & 2 \\
$\mathbf{3}$ & 673 & 3 & 6 & 20 & 71 & 18.5 \\
$\mathbf{4}$ & 673 & 3 & 3 & 0 & 94 & 2 \\
$\mathbf{5}$ & 673 & 3 & 4.5 & 0 & 92.5 & 70 \\
$\mathbf{6}$ & 673 & 3 & 6 & 0 & 91 & 20 \\
$\mathbf{7}$ & 673 & 3 & 9 & 0 & 88 & 18.5 \\
$\mathbf{8}$ & 673 & 3 & 12 & 0 & 85 & 44 \\
$\mathbf{9}$ & 673 & 3 & 12 & 5 & 80 & 70 \\
$\mathbf{1 0}$ & 673 & 3 & 0 & 5 & 92 & 20 \\
$\mathbf{1 1}$ & 673 & 3 & 0 & 0 & 97 & 43.5 \\
$\mathbf{1 2}$ & 298 & 0 & 0 & 0 & 100 & 10 \\
\hline
\end{tabular}

${ }^{1}$ Duration refers to the segments used for XRD evaluation only, i.e. excluding intermediate times of feed gas change.

Electron microscopy was carried out in two modes using a Cs-corrected FEI Titan 80-300 operating at $300 \mathrm{kV}$ : bright field high-resolution transmission electron microscopy (HRTEM) and high angle annular dark field scanning transmission electron microscopy (HAADF STEM). In addition, energy-dispersive X-ray spectroscopy (EDX) was used for elemental mapping of the sample. The samples were crushed, dispersed in ethanol, and deposited on a holey carbon TEM grid. The metal stoichiometry presented in Table 2 was determined by means of energy-dispersive X-ray spectroscopy (EDX) using an EDAX Genesis spectrometer attached to a Hitachi S-4800 microscope operated at $15 \mathrm{kV}$.

\subsection{Catalytic experiments}

Catalytic experiments were carried out in two complementary set-ups. The vast majority of data was measured in a 10 -fold parallel reactor unit that has been described in detail 
before.[18] Gas analysis was performed by an online gas chromatograph (7890A, Agilent). A combination of two capillary columns (PoraplotQ and Plot Molesieve) in connection with a thermal conductivity detector is used to analyze the permanent gases. A combination of two capillary columns (HP-FFAP and PoraplotQ) connected to a flame ionization detector is used to analyze alkanes, olefins, and oxygenates. Catalyst samples were diluted with different amounts of $\mathrm{SiC}(935-1330 \mathrm{mg})$ to yield equal bed heights and thus equal pressure drops in all reactors. Catalyst and diluent were of a sieve fraction of $250-355 \mu \mathrm{m}$. To gain the sieve fraction, catalysts were first pressed at mild conditions ( 2.5 tons on a $13 \mathrm{~mm} \mathrm{die})$, then crushed in an agate mortar, and finally sieved.

Propane is the main reactant, therefore conversion is always related to propane, if not stated otherwise. The conversion of propane was generally calculated from the difference of propane concentration in the effluents of the individual reactors and the blank reactor (Eq. 1).

Eq. 1: $\quad \mathrm{X}_{\text {reactor } \mathrm{n}}=\frac{\mathrm{c}(\text { propane })_{\text {reactor } \mathrm{n}}}{\mathrm{c}(\text { propane })_{\text {blank reactor }}}$

A second way of calculating conversions is to divide the sum of found products by the sum of found products and educts (Eq. 2).

Eq. 2:

$$
\mathrm{X}_{\text {reactor n }}=\frac{\left.\sum_{\text {all products }}(\mathrm{product})_{\text {reactor n }}\right)}{\sum_{\text {all products }}\left(\mathrm{c}(\text { product })_{\text {reactor } n}\right)+\mathrm{c}(\text { propane })_{\text {reactor n }}}
$$

Selectivity was calculated based on the number of carbon atoms, rather than on stoichiometric coefficients, and on the sum of products found (Eq. 3).

Eq. 3:

$$
S(\text { pro duct })=\frac{\frac{\mathrm{n}_{\text {carbo nat oms }}(\mathrm{p} \text { roduct })}{\mathrm{n}_{\text {carbo nat oms }}(\mathrm{p} \text { ropane })} \cdot \mathrm{c}(\text { pr oduct })}{\sum_{\text {al prod ucts }}\left(\frac{\mathrm{n}_{\text {carbo nat oms }}(\mathrm{p} \text { roduct })}{\mathrm{n}_{\text {carbo nat oms }}(\mathrm{p} \text { ropane })} \cdot \mathrm{c} \text { (pr oduct }\right)}
$$


The second set-up (placed in an oven at a temperature of $423 \mathrm{~K}$ to avoid condensation) consisted of a single quartz tube reactor (inner diameter $6.8 \mathrm{~mm}$ ) with a fixed bed of catalyst operated under plug flow conditions. Gas analysis of the reactor effluent was performed by on-line gas chromatography (6890N, Agilent). A combination of two capillary columns (PoraplotQ and Plot Molesieve) in connection with a thermal conductivity detector was used to analyse the permanent gases, water, propane, and propene. A DB-1 capillary column connected to a mass spectrometer as detector was used to analyse oxygenates.

\section{Results}

\subsection{Structural and chemical properties of the catalyst}

Five batches of a phase-pure M1 MoVTeNb oxide catalyst with an average composition of $\mathrm{Mo}_{1.0} \mathrm{~V}_{0.26} \mathrm{Te}_{0.1} \mathrm{Nb}_{0.20}$ and an average specific surface area of $9 \mathrm{~m}^{2} / \mathrm{g}$ (Table 2) are included in the present study.

Table 2

General characteristics of the five reproduced batches of MoVTeNb M1 oxide.

\begin{tabular}{lllllll}
\hline Entry & $\boldsymbol{a} / \boldsymbol{\AA}$ & $\boldsymbol{b} / \AA$ & $\boldsymbol{c} / \AA$ & $\begin{array}{l}\boldsymbol{L}_{\mathbf{V o l}^{-}} \\
\mathbf{I B}^{\mathbf{1}} /\end{array}$ & $\begin{array}{l}\mathbf{A}^{2} / \\
\mathbf{m}^{2} \mathbf{g}^{-1}\end{array}$ & $\begin{array}{l}\text { normalized metal } \\
\mathbf{n m}\end{array}$ \\
& & & & & \\
\hline $\mathbf{6 0 5 9}$ & $21.140(2)$ & $26.632(2)$ & $4.0169(2)$ & $56(2)$ & 8.8 & $\mathrm{Mo}_{1.0} \mathrm{~V}_{0.26} \mathrm{Te}_{0.10} \mathrm{Nb}_{0.22}$ \\
$\mathbf{6 9 0 2}$ & $21.136(2)$ & $26.627(2)$ & $4.0189(2)$ & $56(2)$ & 7.5 & $\mathrm{Mo}_{1.0} \mathrm{~V}_{0.26} \mathrm{Te}_{0.11} \mathrm{Nb}_{0.22}$ \\
$\mathbf{8 6 1 2}$ & $21.163(2)$ & $26.654(2)$ & $4.0187(2)$ & $58(2)$ & 8.5 & $\mathrm{Mo}_{1.0} \mathrm{~V}_{0.26} \mathrm{Te}_{0.10} \mathrm{Nb}_{0.19}$ \\
$\mathbf{8 9 4 7}$ & $21.162(2)$ & $26.651(3)$ & $4.0183(3)$ & $53(3)$ & 10.2 & $\mathrm{Mo}_{1.0} \mathrm{~V}_{0.25} \mathrm{Te}_{0.10} \mathrm{Nb}_{0.19}$ \\
$\mathbf{1 0 7 9 0}$ & $21.1123(13)$ & $26.5911(16)$ & $4.01495(20)$ & $47(1)$ & 9.2 & $\mathrm{Mo}_{1.0} \mathrm{~V}_{0.26} \mathrm{Te}_{0.10} \mathrm{Nb}_{0.19}$ \\
\hline
\end{tabular}

${ }^{\mathrm{T}} L_{\mathrm{Vol}}-\mathrm{IB}$ : mean crystallite size from XRD data; ${ }^{2} \mathrm{~A}$ : specific surface area from $\mathrm{BET}$; ${ }^{3}$ determinned by EDX.

All elements are homogenously distributed within the solids. The results of the XRD measurements confirm that all batches were composed of phase-pure M1 only. Slight variations are observed in the specific surface area and the chemical composition (Table 2). 
These differences might originate from up-scaling effects in the final thermal activation of the different batches. Increasing amounts of the amorphous precursor were annealed in Ar in a rotating furnace resulting in $2 \mathrm{~g}$ (8612), $9 \mathrm{~g}$ (10790), $10 \mathrm{~g}$ (8947), $30 \mathrm{~g}$ (6059), and $40 \mathrm{~g}$ (6902) of the crystalline MoVTeNb M1 oxide.

\subsection{In-situ photoelectron spectroscopy}

Chemical composition and oxidation state of the elements on the surface have been studied by photoelectron spectroscopy in presence of the reactants. The changes in elemental composition near the surface (IMFP $0.6 \mathrm{~nm}$ ) that have been observed when the feed composition was varied are shown in Fig. 1a. The experiment starts with a feed that contains auxiliary steam. After switching from wet to dry feed, the surface composition changes significantly in favour of Mo. The process is reversible by switching the steam on and off. Under wet conditions, vanadium and tellurium are enriched at the surface. The abundance of acrylic acid immediately responds to addition of steam. It becomes obvious that the solid-state kinetics occur more slowly than the kinetics of the gas phase reaction. Fig. 1a shows the abundance of $\mathrm{V}^{5+}$ and not the total $\mathrm{V}$ content, since the amount of $\mathrm{V}^{4+}$ species remains rather unaffected by the steam treatment as can be seen in Fig. 1b. Thus, the ratio between $\mathrm{V}^{5+}$ and $\mathrm{V}^{4+}$ is modified by adding steam to the reaction mixture, i.e., the oxidation state of vanadium changes.

In presence of auxiliary steam, the concentration of vanadium in its highest oxidation state increases in fast response and the abundance of $\mathrm{V}^{5+}$ species correlates with the abundance of acrylic acid. In contrast, the oxidation state of all other elements remains constant. Molybdenum occurs mainly in oxidation state $6+$, tellurium in $4+$, and niobium in $5+$. These results are in good agreement with previously published in-situ photoelectron experiments, in which catalyst 6059 was used.[30] However, in the latter experiments, only a single switch 
from dry to wet feed was performed. Based on the results presented in Fig. 1 a, we can now clearly show that the surface changes, which are induced by changes in the composition of the feed, are indeed reversible.

a)

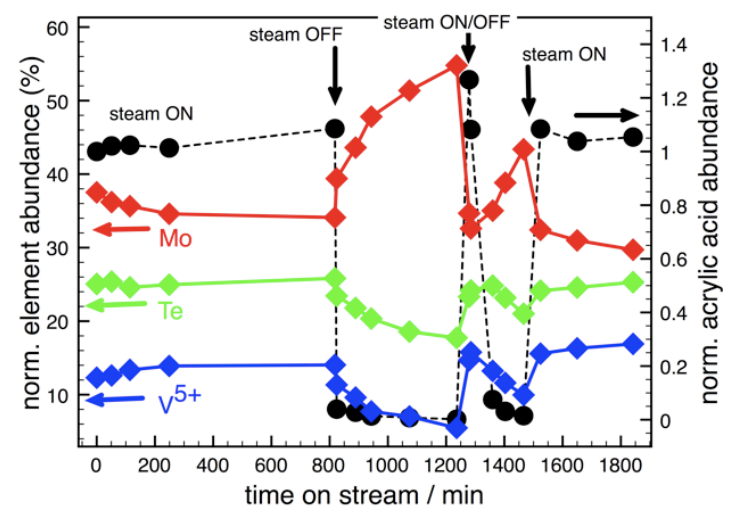

b)

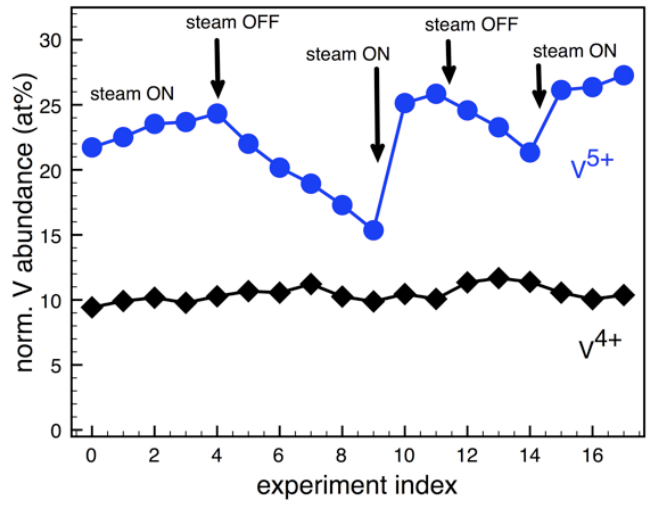

Figure 1. Acrylic acid abundance (black circles) and normalized elemental composition with respect to Mo (red), Te (green), and $\mathrm{V}^{5+}$ (blue) near the surface (0.6nm IMFP) (a), and oxidation state of vanadium (b) under conditions of alternating wet and dry feed of batch 10790; The black diamonds correspond to the $\mathrm{V}^{4+}$ content, the blue circles indicate the total vanadium content, and the difference between the two curves corresponds to the $\mathrm{V}^{5+}$ content.
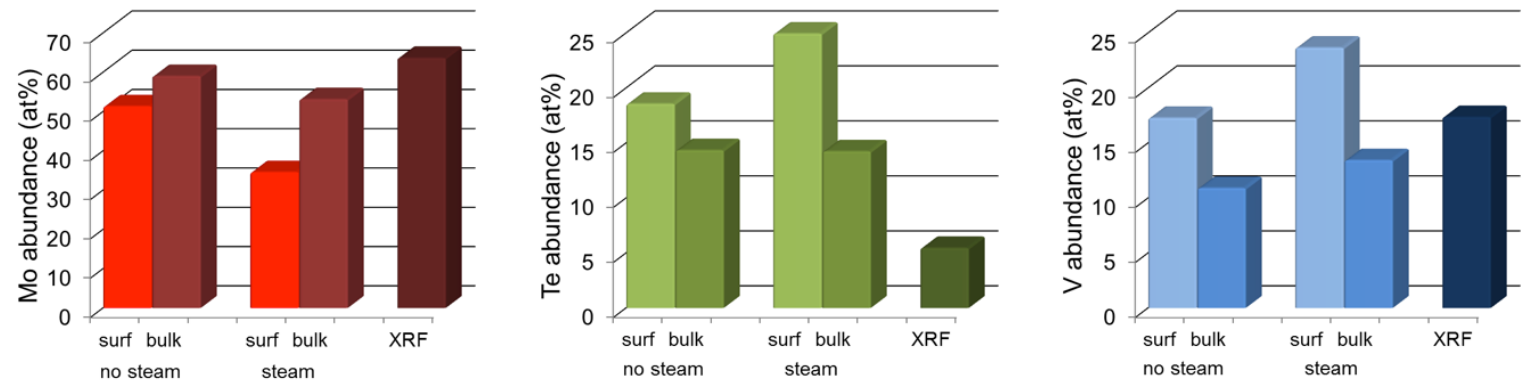

Figure 2. Composition of the surface (0.6 nm IMFP, "surf") and the bulk (1.6 nm IMFP, "bulk") with respect to Mo (red), Te (green), and V (blue) in at.\% under dry and wet feed of batch 10790. These data measured by XPS are compared with the bulk composition analyzed by X-ray fluorescence..

Furthermore, different information depths ("surf" and "bulk") were analysed by applying different excitation energies resulting in different kinetic energies of the released photoelectrons, and thus in a different IMFP (Fig. 2). Under all conditions, vanadium and tellurium are enriched on the surface of the catalyst, while molybdenum is depleted compared to the bulk composition as obtained by X-ray fluorescence (XRF). The analysis at different 
photoelectron escape depths under varying feed conditions clearly shows that the significant changes are restricted to the outermost surface layer of M1.

\subsection{In-situ XRD experiments}

In contrast to the surface, in-situ XRD shows that the bulk structure of the investigated catalyst was remarkably stable under most of the applied conditions. Changes in the XRD patterns were only observed after prolonged time in a strongly reducing feed that consisted only of $3 \%$ propane in He without steam.

All patterns were fitted using only the structural model of M1 as no identifiable ad-phases were detected. The cell constants derived from the Rietveld fits are shown in Fig. 3 for each step, along with the reaction temperature and the averaged data from the mass spectrometer trace related to acrylic acid $(\mathrm{m} / \mathrm{z}=72)$. Fig. 4 shows exemplarily the Rietveld fits for the steps $1,3,10$, and 12 .

It can be clearly seen that temperature has only a small effect on the cell constants of the starting material. Upon heating from 298 to $673 \mathrm{~K}$, the $c$ axis expands less than $0.5 \%$ and the $a$ axis around $0.1 \%$, while the $b$ axis change is negligible. Changes in the reaction atmosphere in steps $3-10$ did not induce any significant change in the lattice constants. There is no influence of steam or oxygen concentration. Acrylic acid productivity shows a maximum in step 3, which is the step with the highest steam content. Apart from that, no clear trends with respect to acrylic acid formation can be observed. 


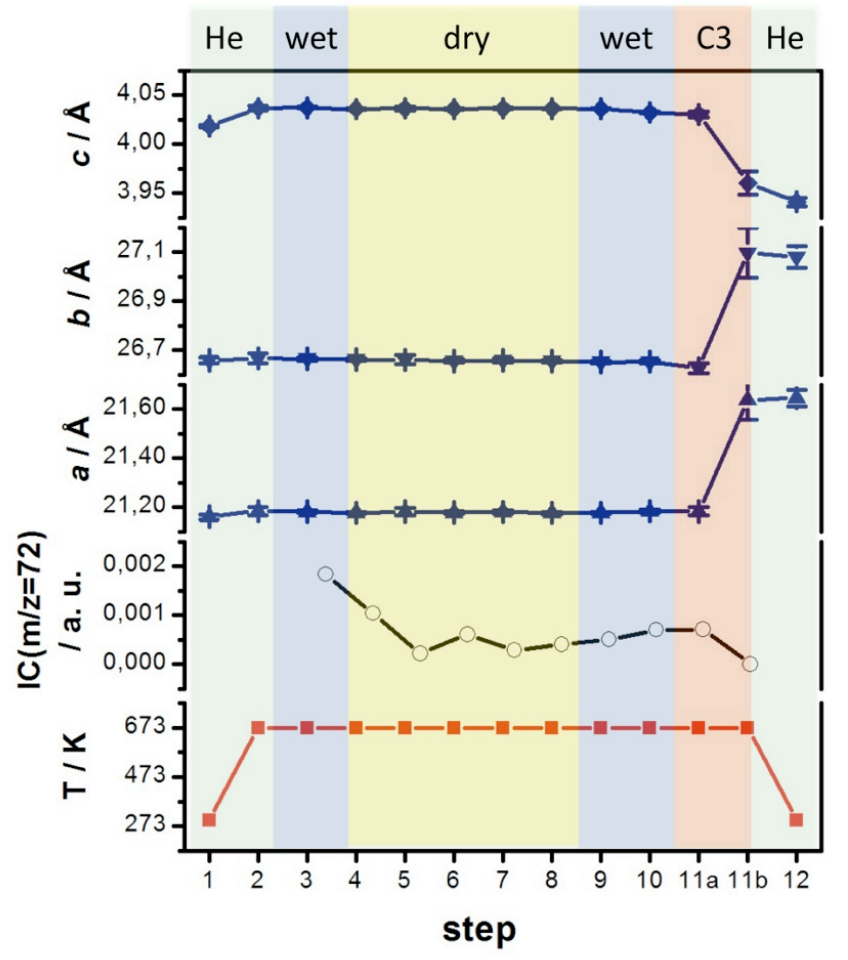

Figure 3. Lattice parameters $a, b$, and $c$ obtained from Rietveld analysis of in-situ XRD patterns of M1 (batch 8612). Error bars represent three estimated standard deviations, which in most cases are equal to or smaller than the symbol size used. The feed composition is illustrated using the colour code as indicated on top of the graph. Details on the steps are given in Tab. 1. Data points $11 \mathrm{a}$ and $11 \mathrm{~b}$ represent the beginning and end of step 11, respectively. From the recorded mass spectrometry data, the average of the normalized ion current of $\mathrm{m} / \mathrm{z}=72$ related to acrylic acid formation is included for each step where propane is in the feed.

Only in presence of propane and absence of both steam and oxygen, i.e., under the most reducing condition investigated, changes occur. Over a time interval of ca. $40 \mathrm{~h}$, the diffraction pattern changed continuously (Fig. 5). The $20-30^{\circ}$ region shown is most representative for the observed changes: on the left hand side, the 001 reflection shifts progressively to the right, while the complex multiplet of peaks on the right side moves to lower angles. It should be noted that all dominant peaks of this multiplet are belonging to the $h k 0$ family. Furthermore, the changes include a decrease of the maximum intensities and increasing peak widths. Rietveld fitting reveals that the patterns can be approximated with a M1 structure model over the whole range, although it should be noted that the agreement 
between the calculated and measured patterns decreases progressively. According to these fits, the $a$ axis is expanded by $2.1 \%$ and the $b$ axis by $1.8 \%$, while the $c$ parameter decreases by $1.7 \%$ during step 11 , thus leading to a unit cell volume increase of about $2.2 \%$. These changes are far more pronounced than the temperature influence on the lattice parameters mentioned above.
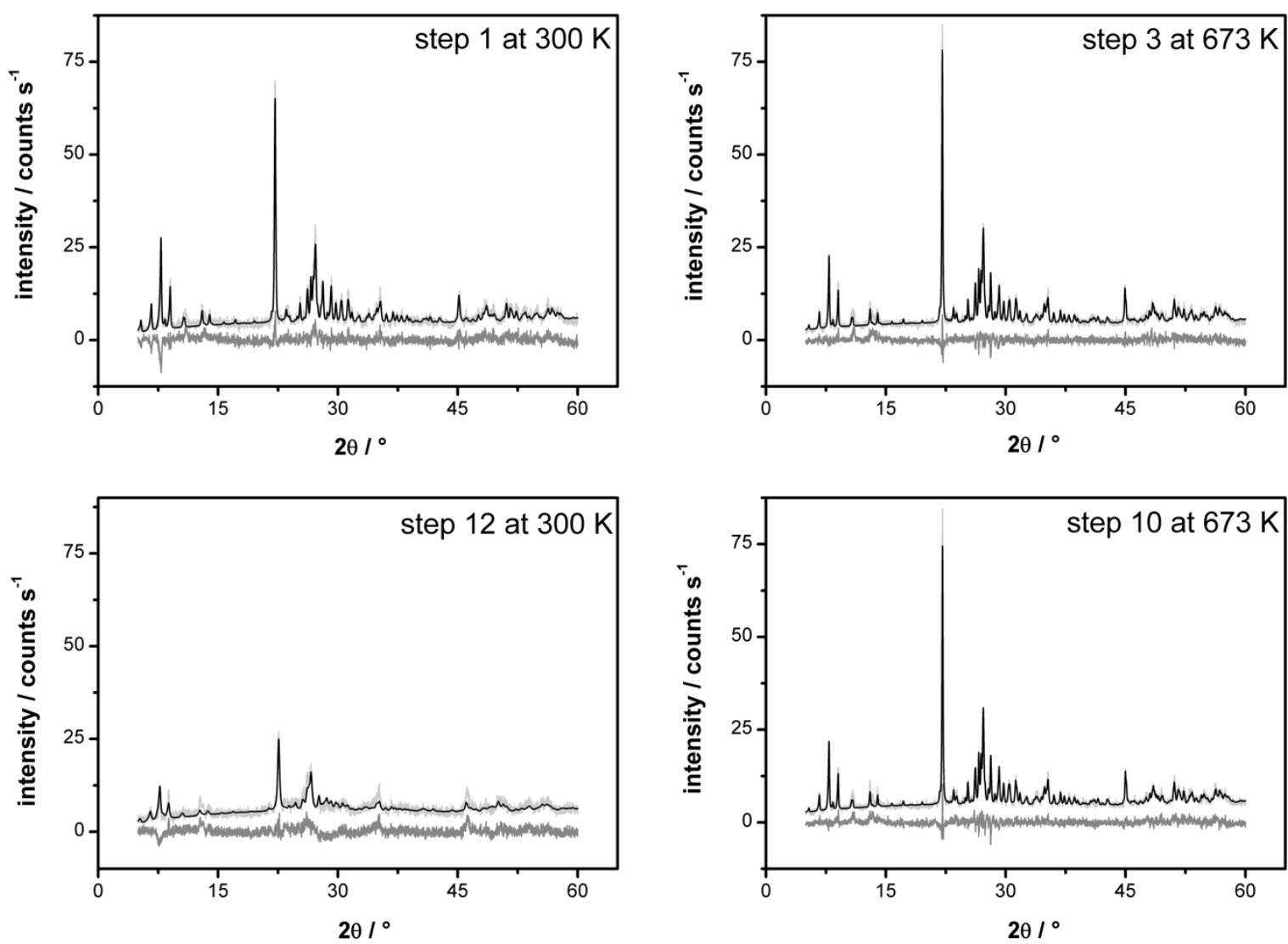

Figure 4. Representative Rietveld fits of M1 (batch 8612) for the step 1 at room temperature in He, step 3 at $673 \mathrm{~K}$ after short time on stream, step 10 at $673 \mathrm{~K}$ after long time on stream, and step 12 after cooling down to room temperature in the feed gas and purging with He. The comparison of step 3 vs. step 1 illustrates the barely noticeable temperature effect, while step 10 vs. step 3 demonstrates the pronounced stability of the catalyst bulk structure over almost 14 days on stream with varied feed compositions. In contrast, step 12 vs. step 10 shows the strong modification and degradation of the M1 structure occurring during step 11 in reducing atmosphere. 


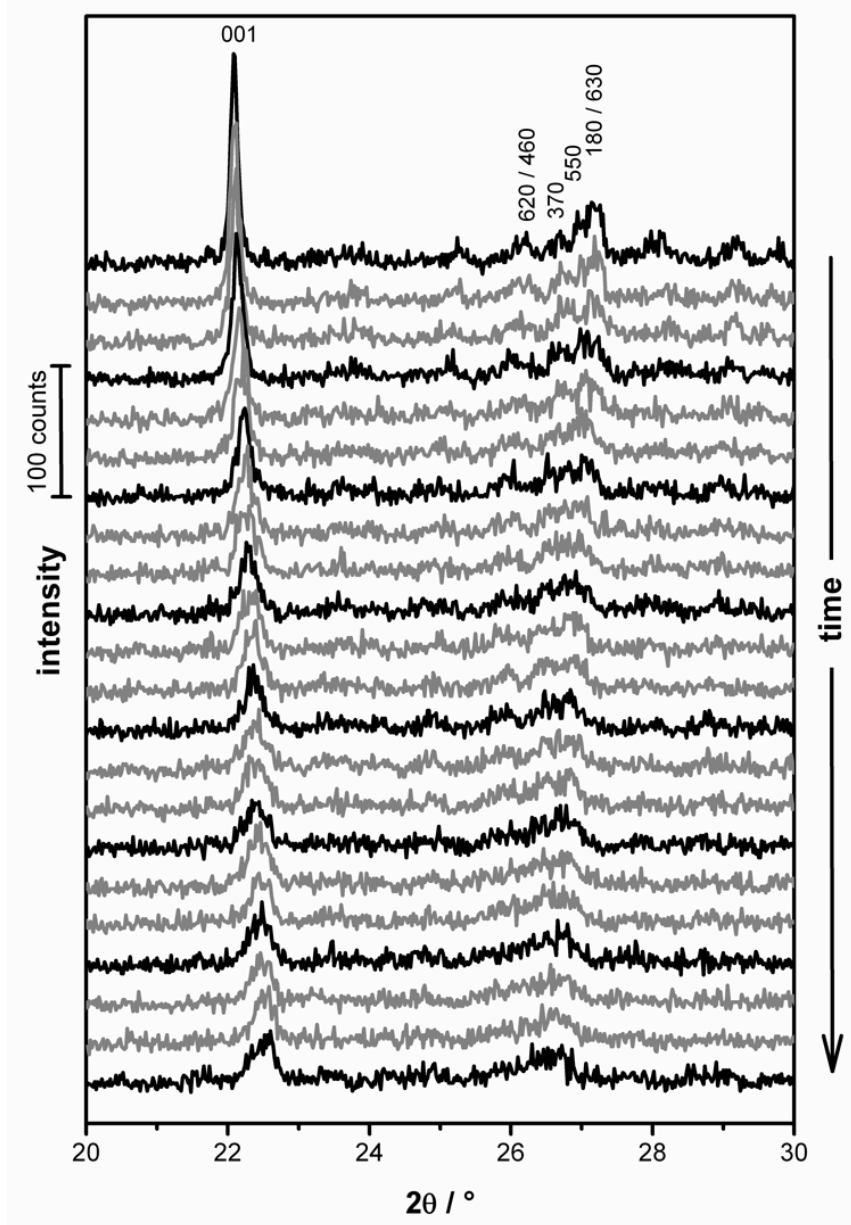

Figure 5. XRD patterns of M1 (batch 8612) measured in-situ during a time interval of 40 hours (from top to bottom) in presence of $3 \%$ propane in He and absence of both steam and oxygen at $673 \mathrm{~K}$ (step 11 in Table 1$)$.

The striking decrease of the maximum intensities seen in Fig. 5 is caused by a superposition of two factors. Firstly, the aforementioned increase in the peak widths, which indicates an accumulation of lattice defects or size reduction of the coherently scattering domains in the crystals, lowers the peak heights. Secondly, the process is accompanied by a ca. $25 \%$ loss of total intensity of the diffraction signal (peak area) of the degrading M1 structure, as estimated from the Rietveld scaling factors of the fits. It should be noted that these continuous changes were probably not yet completed when the experiment was finished and the sample cooled down in the feed gas. Thus, the lattice parameters of step 12 in comparison to the end of step 
11 show a combination of a small temperature effect (contraction) with some ongoing chemical modifications.

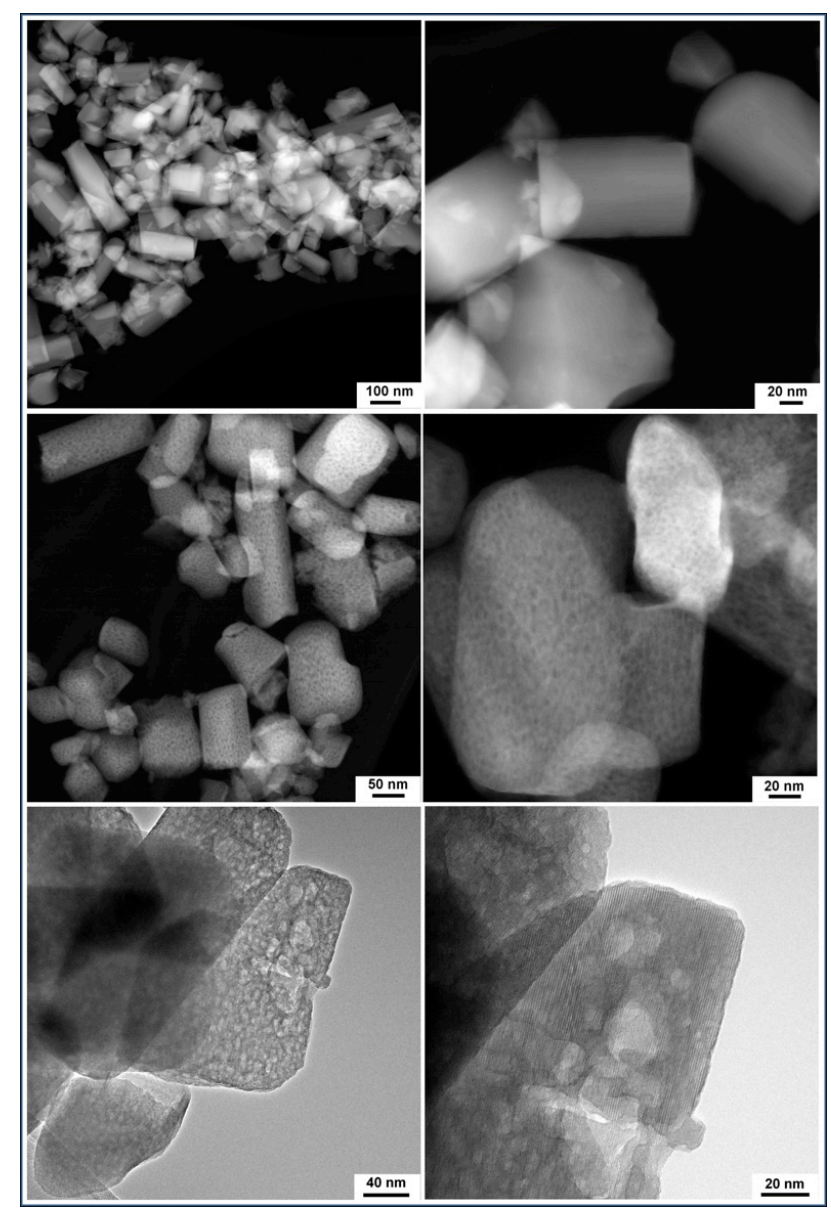

Figure 6. HAADF-STEM before (batch 8612, top two images) and after in-situ XRD (ID 9600, middle two images) reveals changes in the particle morphology while HRTEM of the used batch (bottom two images) shows that the crystalline structure remains unchanged.

A comparison of the micropraphs taken of the sample before and after the in-situ XRD experiments shows that the overall particle shape itself did not change (Fig. 6). The sample consists after the experiments still of large needles, but the appearance of the needles is severely damaged. It seems that the needles are thrilled by a large number of holes, which can be seen in HRTEM micrographs as well as in HAADF STEM micrographs. The results obtained by EDX indicate that $\mathrm{V}, \mathrm{Mo}$, and $\mathrm{Nb}$ are still homogenously distributed in the sample (Fig. 7). Tellurium seems to be enriched locally in the vicinity of the rim of the 
craters. EDX analysis of individual scans reveals a formula of $\mathrm{Mo}_{1.00} \mathrm{~V}_{0.26} \mathrm{Te}_{0.04} \mathrm{Nb}_{0.13} \mathrm{O}_{4.2}$ indicating Te loss in various areas.

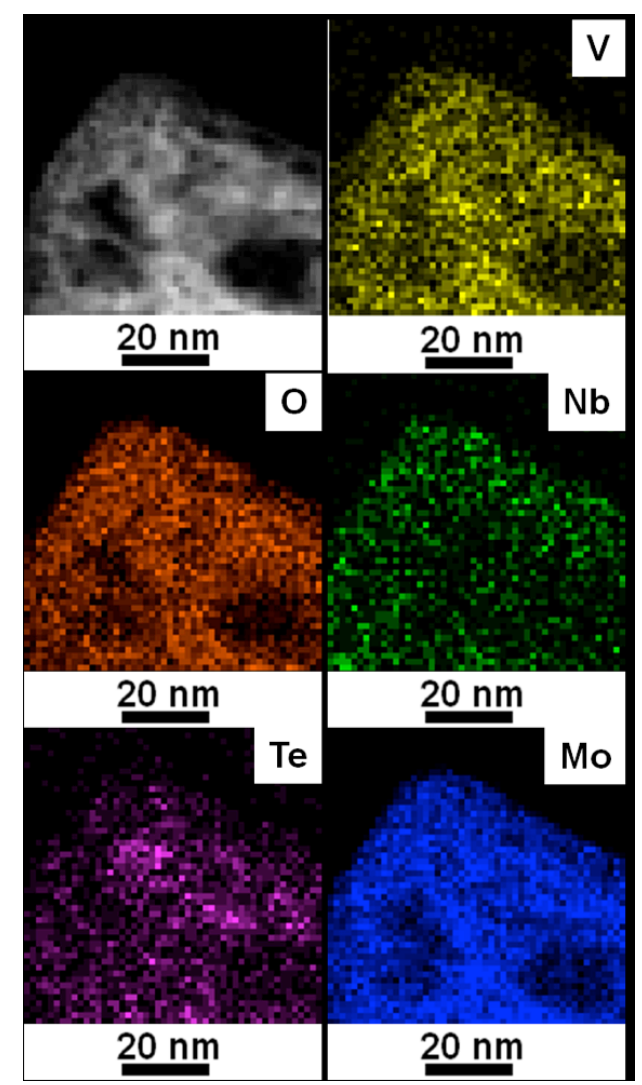

Figure 7. STEM-EDX map revealing the distributions of elements after in-situ XRD (batch 8612 after catalysis-ID 9600).

In summary, the results of electron microscopy show that the sample after reaction and final treatment in reducing atmosphere still consists of large M1-like needles and there is no indication for segregation of any phases or the presence of large amounts of amorphous material, but the morphology of the primary M1 particles is damaged. The damage may be induced by the reduction and evaporation of elemental tellurium under purely reducing conditions that leads to a local collapse of the crystal structure and the formation of holes.

\subsection{Oxidation of propane}

In agreement with the results of the in-situ XRD experiment, phase-pure M1 does not deactivate in propane oxidation, even when temperature, contact time, and feed composition 
are varied in a broad range over a long time. Stability has been confirmed by returning temporarily to standard conditions $\left(3 \% \mathrm{C}_{3} \mathrm{H}_{8}, 6 \% \mathrm{O}_{2}, 40 \%\right.$ steam, balanced with $\mathrm{N}_{2}$, $\mathrm{T}=663 \mathrm{~K}$ ). The yield of acrylic acid for a contact time of $0.72 \mathrm{~s} \mathrm{~g} \mathrm{Nml}^{-1}$ is shown as a function of time in Figure 8. No deactivation occurred during 10 months of time-on-stream within the error of the measurement in the 10 -fold parallel reactor. This result shows that phase-pure M1 is a stable catalyst even when reaction conditions change drastically. In addition, it shows that the kinetic measurements are unimpaired by catalyst deactivation.

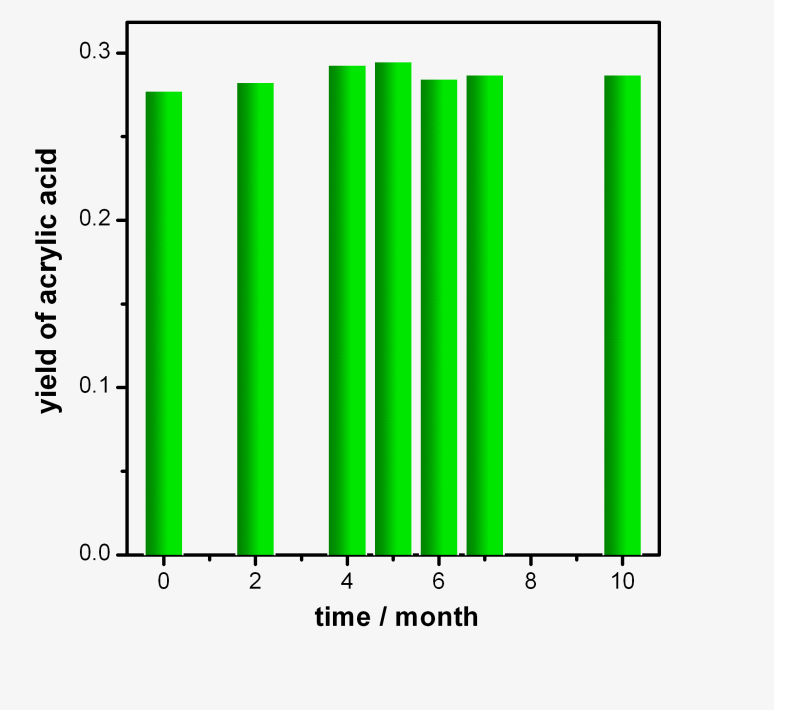

Figure 8. Yield of acrylic acid measured repeatedly in the course of ten month under standard conditions ( $3 \%$ propane, $6 \%$ oxygen, $40 \%$ steam) at a temperature of $663 \mathrm{~K}$ and a contact time of $0.72 \mathrm{~s} \mathrm{~g} \mathrm{Nml}^{-1}$ (batch 6902).

Regardless of the experimental conditions, the only products detected under the applied reaction conditions in concentrations above $10 \mathrm{ppm}$ were propene, acrylic acid, acetic acid, and the products of deep oxidation carbon monoxide and carbon dioxide. Fig. 9 shows the selectivity $\mathrm{S}$ to these products as function of conversion $\mathrm{X}$ (S-X plot) given by different reaction temperatures from 623 to $663 \mathrm{~K}$, different feed compositions, and different contact times. The figure contains all data measured at contact times up to $0.72 \mathrm{~s} \mathrm{~g} \mathrm{Nml}^{-1}$. Data points measured at the highest applied contact time $\left(1.44 \mathrm{~s} \mathrm{~g} \mathrm{Nml}^{-1}\right)$ are not included as they scatter to a large degree mainly caused by increased total oxidation. The selectivity is strongly 
influenced by the steam concentration. Therefore, data shown in Fig. 9 are presented in four groups according to the steam concentration of the feed gas. Fig. 10 shows the same data under differential conditions (conversion below 0.1).
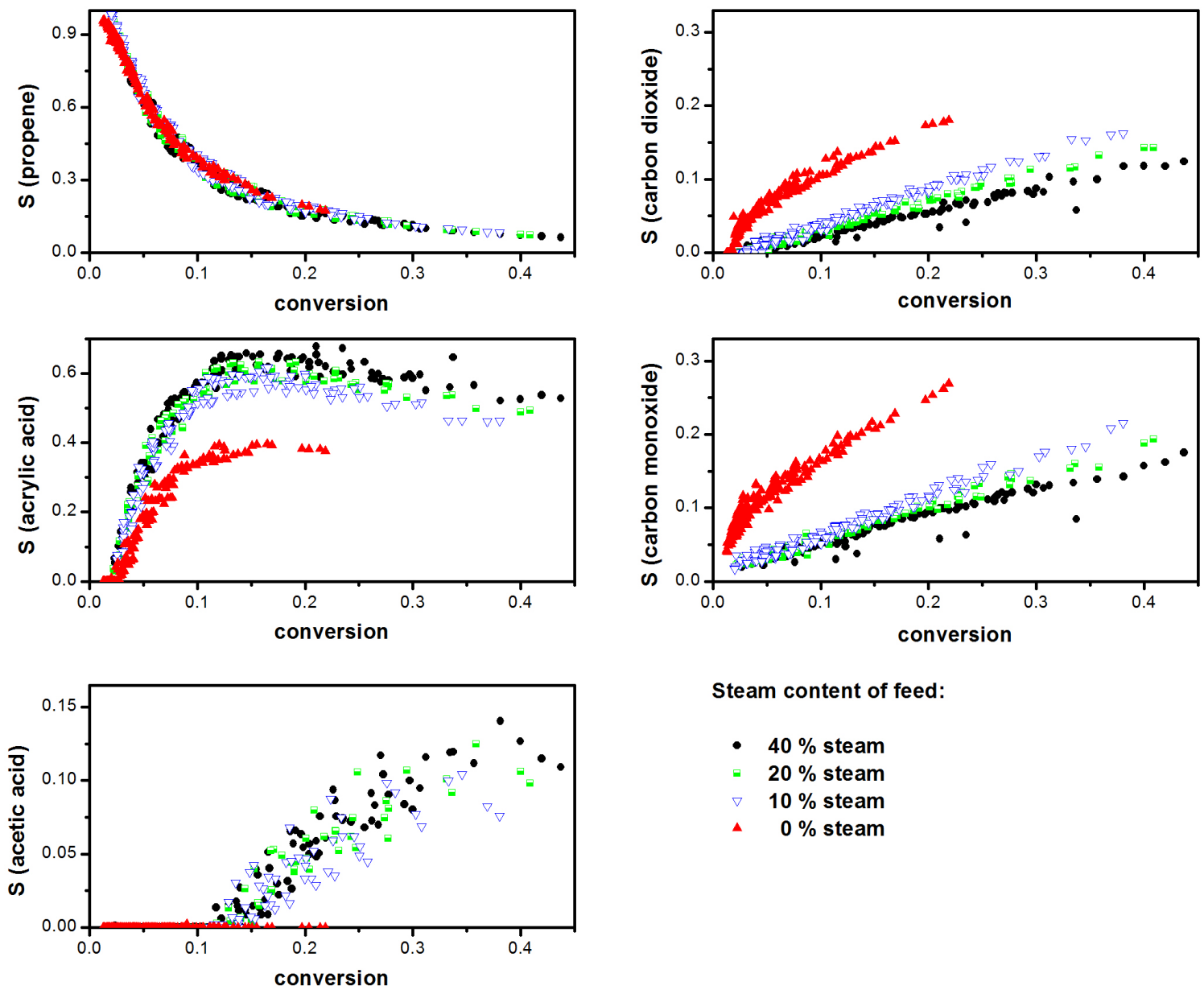

Steam content of feed:

- $40 \%$ steam

$20 \%$ steam

$10 \%$ steam

- $0 \%$ steam

Figure 9. Selectivity versus propane conversion for all observed products measured at temperatures from $623 \mathrm{~K}$ to $663 \mathrm{~K}$ and contact times below $1 \mathrm{~s} \mathrm{~g} \mathrm{Nml}^{-1}$ using feed gas mixtures containing $3 \%$ propane, $4.5-12 \%$ oxygen, and $0-40 \%$ steam (batch 6902 ); data is presented in groups measured in feed gas mixtures of the same steam content.

Some general trends are easily recognizable. The data shown in Fig. 9 correspond to the same range of contact times under all investigated conditions. The maximum conversion of propane reached at the highest contact time increases with increasing steam content of the feed. The influence of steam on the selectivity to propene is negligible. In contrast, the selectivity to acrylic acid is strongly influenced by the steam content of the feed. 

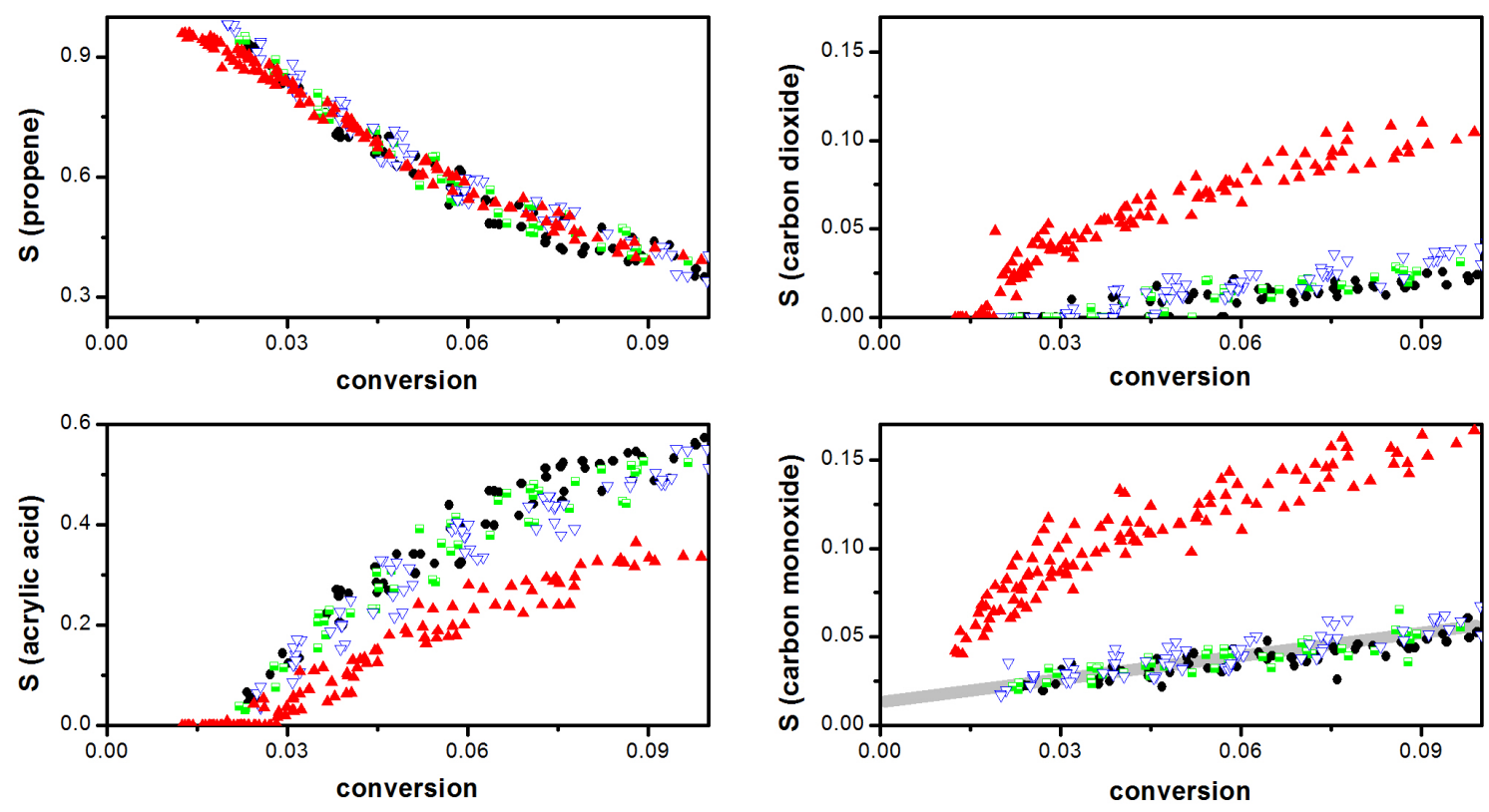

Steam content of feed: - $40 \%$ steam

$20 \%$ steam $\nabla \quad 10 \%$ steam $\quad 0 \%$ steam

Figure 10. Selectivity versus propane conversion for all observed products in the differential regime $(\mathrm{X}<0.1)$ measured at temperatures from $623 \mathrm{~K}$ to $663 \mathrm{~K}$ using feed gas mixtures containing 3\% propane, $4.5-12 \%$ oxygen, and $0-40 \%$ steam (batch 6902); data is presented in groups measured in feed gas mixtures of the same steam content. The grey line in the plot of the selectivity of carbon monoxide is included to guide the eye, indicating that extrapolation of data measured in wet feed to $\mathrm{X}=0$ yields a positive intercept of ca. $1.5 \%$.

There is no formation of acetic acid in dry feed. In wet feed, the formation of acetic acid starts in the range in which the selectivity to acrylic acid has its broad maximum. No clear trends connected to the steam content of wet feed can be observed for acetic acid.

The selectivity to carbon dioxide and carbon monoxide are decreasing with increasing steam content of the feed. A difference between the two products can be definitely found in the differential regime. Carbon dioxide is clearly a secondary product in wet and dry feed, and the selectivity reaches zero at lowest conversions measured. In contrast, carbon monoxide appears to be a primary product under conditions of wet feed. The S-X plot can be extrapolated to $X=0$ yielding a positive intercept around $S=0.015$. An unambiguous extrapolation of the data measured under dry conditions to $\mathrm{X}=0$ is, however, not possible due to restrictions with respect to the detection limit of the TCD detector. 


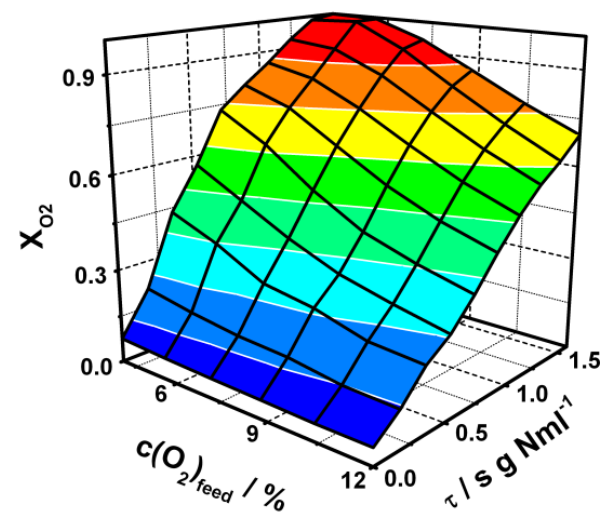

$663 \mathrm{~K}$

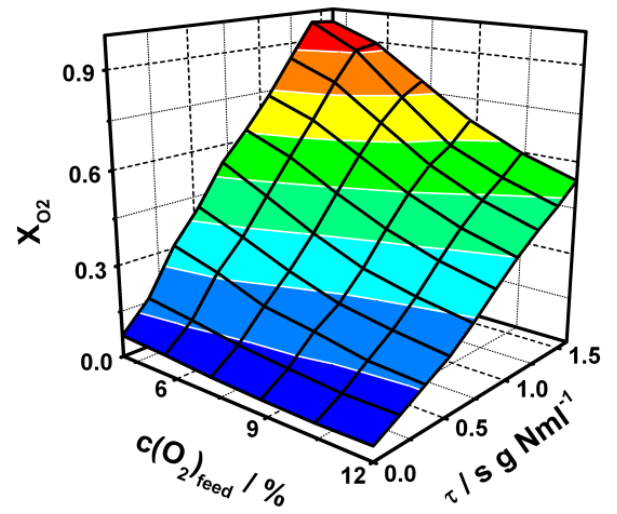

$643 \mathrm{~K}$

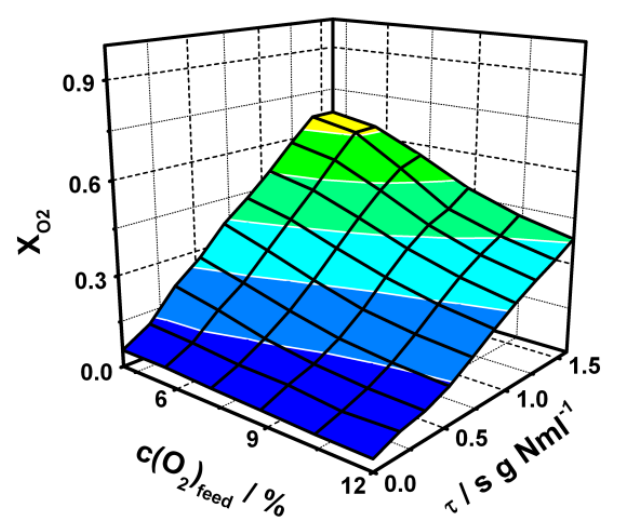

$623 \mathrm{~K}$

Figure 11. Conversion of oxygen as function of oxygen concentration in the feed, contact time, and temperature measured using feed gas mixtures containing $3 \%$ propane and $40 \%$ steam (batch 6902).

The fact that the data measured at the longest contact time of $1.44 \mathrm{~s} \mathrm{~g} \mathrm{Nml}^{-1}$ scatters too much to be included into Fig. 9 can be rationalized by the different degrees of oxygen conversion reached in feed with different oxygen content. Fig. 11 shows the oxygen conversion as function of oxygen content of the feed and contact time for high, medium and low 
temperature, measured in feed containing $40 \%$ steam. It can be clearly seen that already at medium temperatures full conversion of oxygen is reached in feed with low oxygen content. Catalytic data measured under such conditions where the availability of oxygen for reaction is limited cannot be directly compared to data measured at moderate oxygen conversion.
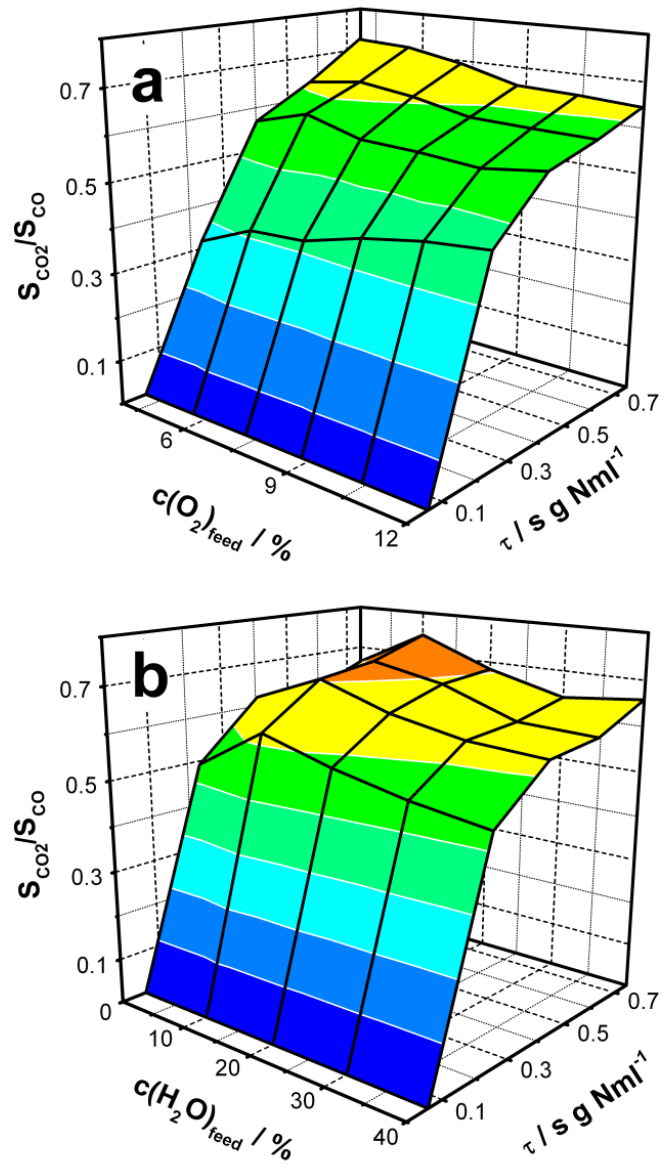

Figure 12. Influence of oxygen and steam feed concentration on the ratio of the selectivity of carbon dioxide to the selectivity of carbon monoxide measured at a temperature of $643 \mathrm{~K}$ using feed gas mixtures containing $3 \%$ propane, $40 \%$ steam and various oxygen contents (a), and feed gas mixtures containing $3 \%$ propane, $12 \%$ oxygen, and various steam contents (b) (batch 6902). 

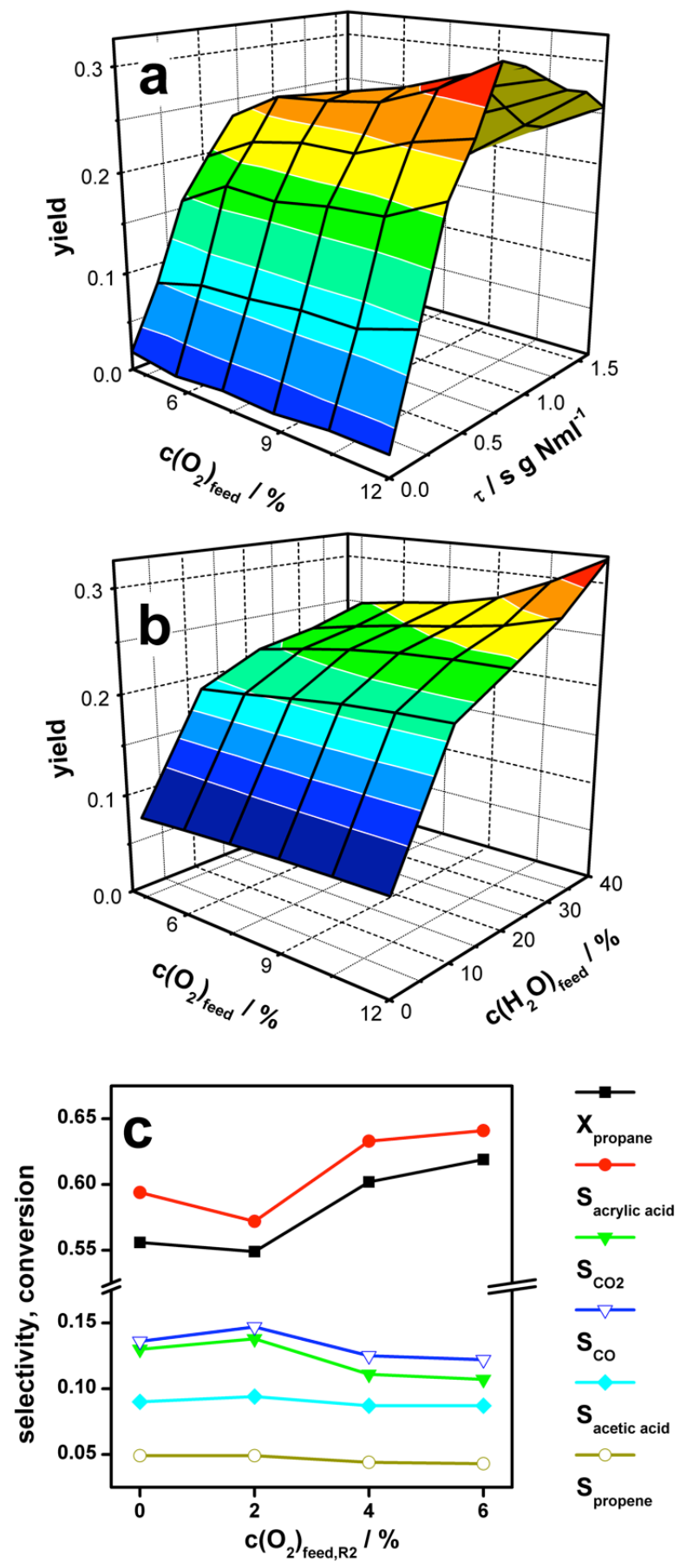

Figure 13. (a) Influence of contact time and oxygen concentration of the feed on the yield of acrylic acid measured at a temperature of $653 \mathrm{~K}$ in feed gas mixtures containing $3 \%$ propane and $40 \%$ steam (batch 6902). (b) Influence of steam and oxygen concentration of the feed on the yield of acrylic acid measured at $653 \mathrm{~K}$ and a contact time of $0.72 \mathrm{~s} \mathrm{~g} \mathrm{Nml}^{-1}$ (batch 6902). (c) Results of addition of $\mathrm{O}_{2}$ between two reactors in series operated at a temperature of $673 \mathrm{~K}$ and a contact time of $0.4 \mathrm{~s} \mathrm{~g} \mathrm{Nml}^{-1}$ per reactor in an initial feed containing $3 \%$ propane, $6 \%$ oxygen and $40 \%$ steam balanced with nitrogen (amount of $\mathrm{O}_{2}$ added between the two reactors in vol\% is indicated on the x-axis); (batch 6059). 
Fig. 12 illustrates the influence of contact time, oxygen, and steam content of the feed on the ratio between the selectivity to carbon dioxide and carbon monoxide. For oxygen and steam no clear trends can be observed, but the contact time has a strong influence. The fact that different ratios exist indicates that $\mathrm{CO}$ and $\mathrm{CO}_{2}$ are not formed along a single reaction path with fixed stoichiometry. This is in agreement with the observation that $\mathrm{CO}$ might be a primary product, while $\mathrm{CO}_{2}$ is certainly a secondary product.

The yield of acrylic acid passes through a maximum. The highest yield was measured in a feed containing $3 \%$ propane, $12 \%$ oxygen and $40 \%$ steam, at a temperature of $653 \mathrm{~K}$ and a contact time of $0.72 \mathrm{~s} \mathrm{~g} \mathrm{Nml}^{-1}$ (Fig. 13 a). Regardless of the oxygen content, the highest yield was measured at a contact time of $0.72 \mathrm{~s} \mathrm{~g} \mathrm{Nml}^{-1}$ in presence of $40 \%$ staem in the feed. The same effect can be observed at any other temperature included in this study. At longer contact time, the yield of acrylic acid is lowered mainly due to increased formation of carbon dioxide and carbon monoxide. Over the whole range of contact time it can be seen that higher oxygen content of the feed gives a higher yield. This effect is not due to an increase in selectivity, but to an increase in conversion. Fig. $13 \mathrm{~b}$ illustrates the influence of steam and oxygen content of the feed on the acrylic acid yield measured at $653 \mathrm{~K}$ and a contact time of $0.72 \mathrm{~s} \mathrm{~g} \mathrm{Nml}^{-1}$. The largest difference is between dry feed and wet feed. It can be seen that the highest yield is obtained at highest steam and highest oxygen contents. Fig. $13 \mathrm{c}$ shows results measured with two single tube reactors connected in series. Both reactors were operated at $673 \mathrm{~K}$ and a nominal contact time of $0.4 \mathrm{~s} \mathrm{~g} \mathrm{Nml}^{-1}$, giving a total contact time of $0.8 \mathrm{~s} \mathrm{~g} \mathrm{Nml}^{-1}$. The feed for the first reactor consisted of $3 \%$ propane, $6 \%$ oxygen, and $40 \%$ steam balanced with nitrogen. Between the two reactors oxygen was added to the effluent gas of the first reactor. The amount of oxygen that was added is indicated on the x-axis of Fig. 13 c. The added oxygen results in an additional consumption of propane in favour of the formation of acrylic acid. The selectivity to all other products decreases, which is in agreement with the 
experimental results obtained with increasing oxygen partial pressure in the parallel reactor. Obviously both oxygen and steam content are of importance for the yield of acrylic acid, but the effect of increasing steam content is still stronger than the effect of increasing oxygen concentration. This can be rationalized by the fact that increased steam content increases the selectivity to acrylic acid and the conversion of propane (Fig. 9). Higher steam contents were not included in this study for practical reasons only as higher contents could not be generated at constant and stable levels in the parallel set-up. Higher oxygen contents were not included into the study for safety and technical reasons. Propane has a low explosion limit of $2 \%$ in air (i.e., in $21 \%$ oxygen). An oxygen concentration of $12 \%$ in a feed containing $40 \%$ of steam is about the maximum obtainable with air as oxygen source and it seemed reasonably far away from explosive conditions.

Initial rates of propane consumption were calculated by linearization of plots of conversion versus contact time for all combinations of steam content, oxygen content and temperature in the range below $0.2 \mathrm{~s} \mathrm{~g} \mathrm{Nml}^{-1}$. With these rates apparent overall activation energies for the consumption of propane could be calculated as well as reaction orders of oxygen. Fig. 14 a shows the influence of steam and oxygen content of the feed on the apparent activation energy. The largest effect can be seen when feed conditions change from dry to wet feed. The activation energy obtained for dry feed gas lies in the range of $80-95 \mathrm{~kJ} \mathrm{~mol}^{-1}$, while it lies in the range of $55-75 \mathrm{~kJ} \mathrm{~mol}^{-1}$ for wet feed. Regardless of the steam content, the lowest activation energies (ca. $60 \mathrm{~kJ} \mathrm{~mol}^{-1}$ ) were obtained at the lowest oxygen content of the feed (4.5\%). The activation energy increases to ca. $72 \mathrm{~kJ} \mathrm{~mol}^{-1}$ when the oxygen content increases to $6 \%$. In the range of $6-12 \%$ of oxygen content, the activation energy increases slightly in $10 \%$ of steam, decreases slightly in $20 \%$ of steam and decreases strongly in $40 \%$ of steam. Thus the largest influence of steam on the activation energy is observed for oxygen contents of $12 \%$. 
The reaction order of oxygen can also be obtained for different steam contents and temperatures; results are summarized in Fig. 14 b. No clear trends can be found, but the average reaction order is about 0.12 indicating that the oxygen content has only a small but positive influence on the propane consumption rates. This positive influence cannot be attributed to an increased total oxidation of propane or products as the selectivity is hardly influenced by the oxygen content of the feed (Fig. 10).
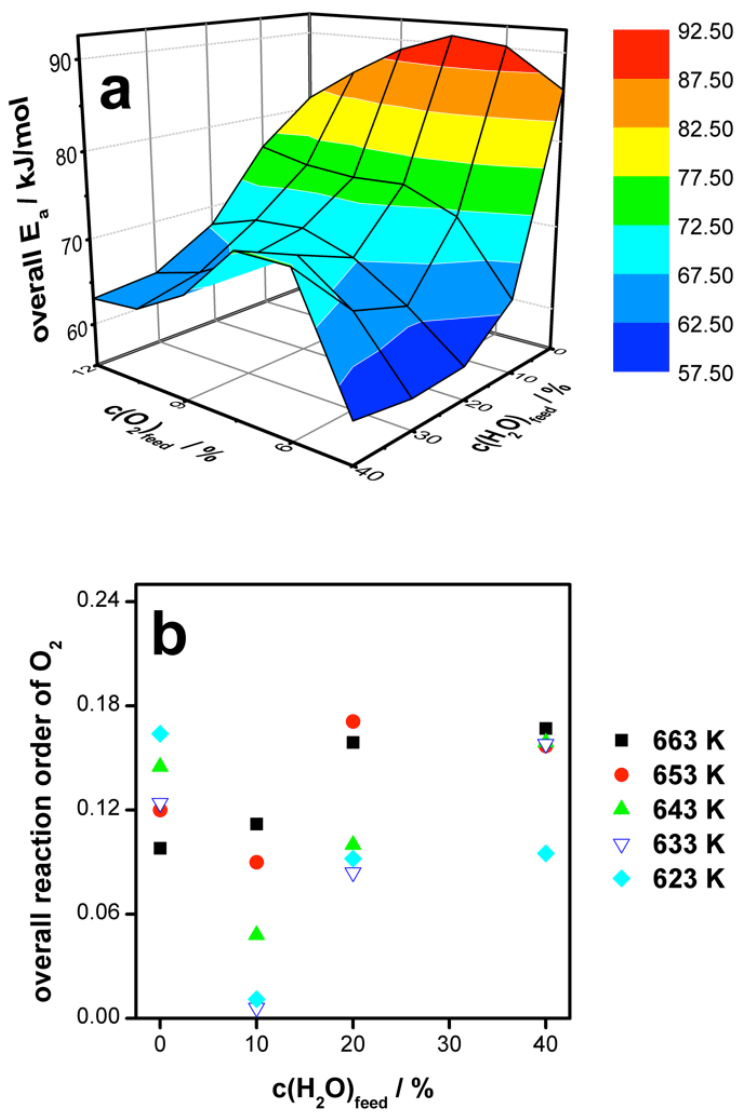

Figure 14. (a) Influence of oxygen and steam concentration of the feed on the overall activation energy of propane consumption based on initial reaction rates measured in the temperature range $623-663 \mathrm{~K}$ (batch 6902); (b) Influence of temperature and steam concentration of the feed on the overall reaction order of oxygen; based on initial reaction rates measured in the temperature range $623-663 \mathrm{~K}$ (batch 6902). 


\subsection{Reference experiments}

Additional experiments were carried out in a single-tube reactor to gain further insight into the reaction network of propane oxidation.

The oxidation of propene was investigated, as propene is the main product at short contact times. Fig. 15 a shows the influence of steam content of the feed on the oxidation of propene. Although the conversion of propene is much higher compared to the conversion of propane under similar conditions, the effect of steam is the same. In dry feed the conversion is drastically lower, in wet feed the conversion increases with increasing steam content. Under all conditions the selectivity to acrylic acid is high at levels in the range of $0.6-0.75$. The lowest selectivity is found in dry feed. The fact that the selectivity to acrylic acid in wet feed slightly decreases with increasing steam content can be rationalized by the fact that the conversion increases. Selectivity to carbon dioxide and to carbon monoxide are higher in dry feed than in wet feed, again similar to the results obtained for propane oxidation. In wet feed the selectivity to carbon monoxide is not influenced by the steam content, while the selectivity to carbon dioxide decreases slightly with increasing steam content. Selectivity to acetic acid is very low and no correlation with the steam content can be observed. In contrast to results obtained in propane oxidation, acetone was detected in wet feed with selectivity lying in the range of $0.05-0.15$. In dry feed no acetone was detected.

Fig. $15 \mathrm{~b}$ shows results measured with two reactors connected in series. Both reactors were operated at $673 \mathrm{~K}$ and a nominal contact time of $0.4 \mathrm{~s} \mathrm{~g} \mathrm{Nm}^{-1}$, giving a total contact time of $0.8 \mathrm{~s} \mathrm{~g} \mathrm{Nml}^{-1}$. The feed for the first reactor consisted of $3 \%$ propane, $6 \%$ oxygen, and $40 \%$ steam balanced with nitrogen. Between the two reactors propene was added to the effluent gas of the first reactor. The nominal propene content of the feed (calculated for zero propane conversion in the first reactor) was set to $0,0.5$ and $0.75 \%$. Interestingly, no acetone was detected under these conditions in full agreement with results obtained for propane oxidation. 
Neither the integral consumption rate of propane nor the integral formation rate of propene is significantly affected by the addition of propene, indicating that all added propene was fully converted. The integral formation rate of all other products increased with the addition of propene. The strongest increase was found for acrylic acid.
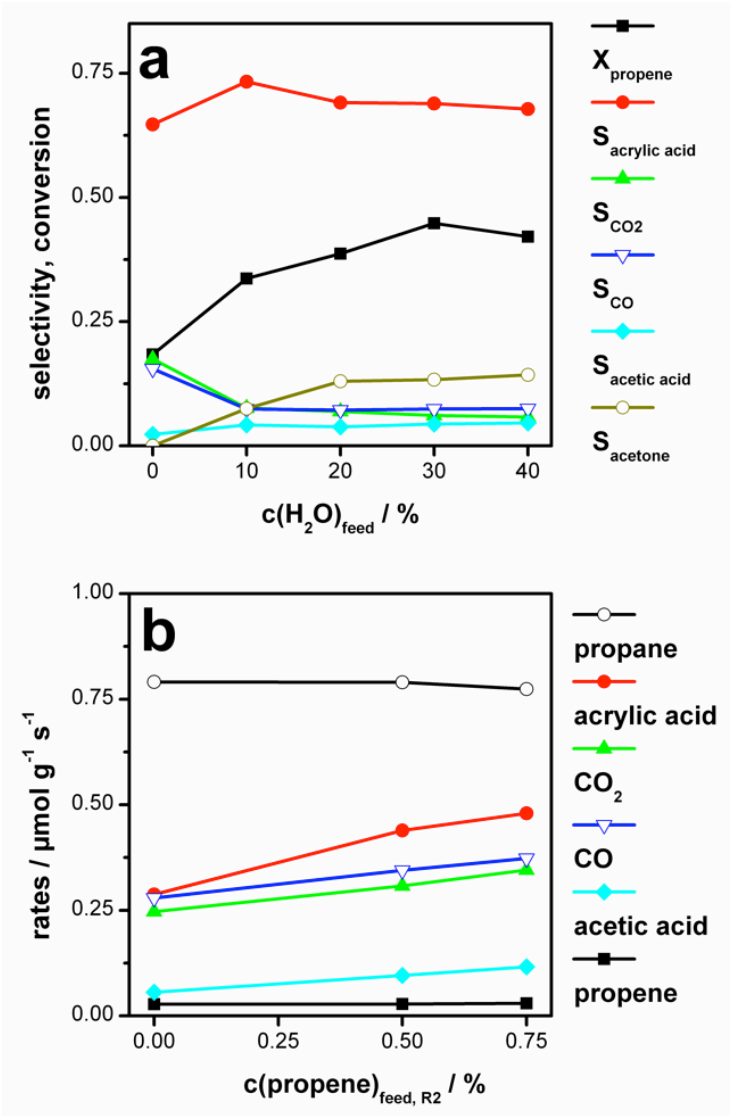

Figure 15. Influence of steam on the oxidation of propene measured at a temperature of $673 \mathrm{~K}$ and a contact time of $0.45 \mathrm{~s} \mathrm{~g} \mathrm{Nml}^{-1}$ in a feed containing $3 \%$ propene and $6 \%$ oxygen (batch 6059) (a). Results of addition of propene between two reactors in series operated at a temperature of $673 \mathrm{~K}$ and a contact time of $0.4 \mathrm{~s} \mathrm{~g} \mathrm{Nml}^{-1}$ per reactor in an initial feed containing $3 \%$ propane, $6 \%$ oxygen and $40 \%$ steam balanced with nitrogen (batch 6059 ) (b).

A possible intermediate product in the synthesis of acrylic acid is acrolein. Therefore the oxidation of acrolein was investigated under conditions similar to those applied for propane oxidation. Conversion and selectivity data as function of temperature are shown in Fig. 16. 
The conversion of acrolein is even at $633 \mathrm{~K}$ at ca. 0.75 , at $673 \mathrm{~K}$ the conversion is ca. 0.95 . The influence of water was not further studied as already the addition of $10 \%$ steam led to full conversion at $633 \mathrm{~K}$ in agreement with the observation that acrolein was not found as a product under reaction conditions of propane oxidation. The oxidation of acrolein gave acrylic acid as main product with selectivity above 0.9 . The only other products detected were acetic acid, carbon dioxide and carbon monoxide. At the lowest temperature and conversion acetic acid was the main by-product. With increasing temperature and conversion the selectivity of acetic acid decreased, while the selectivity to carbon dioxide and to carbon monoxide increased.

Several experiments were carried out to probe whether carbon monoxide is a stable final product, or whether it can be further oxidized to carbon dioxide. The oxidation of carbon monoxide was investigated at a temperature of $673 \mathrm{~K}$ and contact times between 0.3 and $1.2 \mathrm{~s} \mathrm{~g} \mathrm{Nml}^{-1}$ in a feed containing $3 \%$ carbon monoxide. The reaction was investigated in dry feed at two different $\mathrm{CO} / \mathrm{O}_{2}$ ratios, i.e. in stoichiometric feed $\left(\mathrm{CO} / \mathrm{O}_{2}=2\right)$ and in excess of oxygen $\left(\mathrm{CO} / \mathrm{O}_{2}=0.5\right)$. In wet feed gas $(40 \%$ steam $)$ the reaction was investigated in excess of oxygen $\left(\mathrm{CO} / \mathrm{O}_{2}=0.5\right)$ and in absence of oxygen (water-gas-shift reaction). The results are summarized in Fig. 17. The conversion of carbon monoxide is very low $(X<0.015)$ under all investigated conditions. The lowest conversions were measured in case of the water-gas-shift reaction. The highest conversion was measured in wet feed gas in excess of oxygen. In dry feed gas the $\mathrm{CO} / \mathrm{O}_{2}$ ratio had no influence on the conversion. Although the conversion measured in wet feed gas and excess of oxygen is not the sum of the conversions measured in dry feed gas and for the water-gas-shift reaction, it can be assumed that both reactions occur in parallel.

In two experiments similar to the propene addition experiment using two reactors connected in series (Fig. 15 b), carbon monoxide and carbon dioxide were added to the effluent of the 
first reactor. In both cases no influence of the added species on propane conversion or selectivity could be observed (results not shown). All added species could be found unchanged in the effluent of the second reactor.

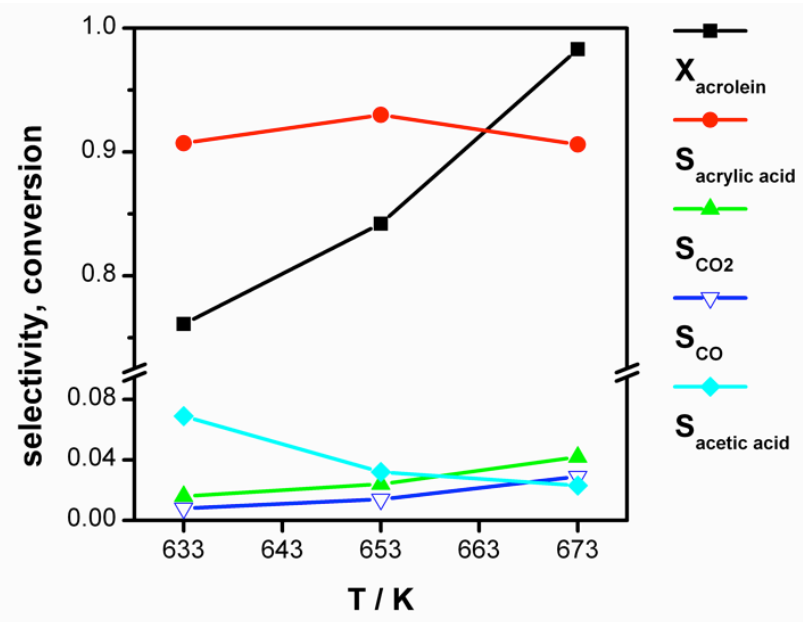

Figure 16. Conversion and selectivity measured for the oxidation of acrolein as a function of temperature measured at a contact time of $0.015 \mathrm{~s} \mathrm{~g} \mathrm{Nml}^{-1}$ in a dry feed containing $3 \%$ acrolein and $6 \%$ oxygen (batch 6059).

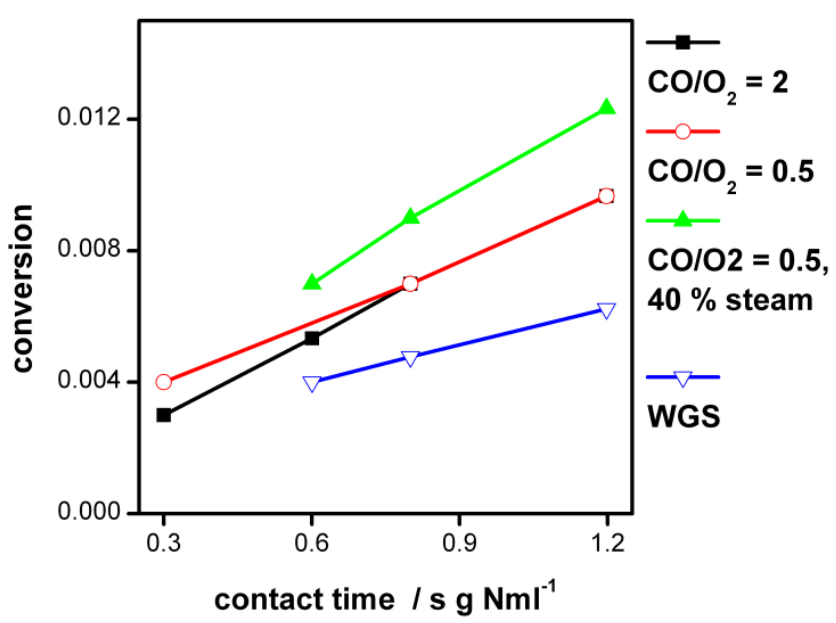

Figure 17. CO oxidation and water gas shift reaction (batch 6059).

Fig. 18 compares on a logarithmic scale the reaction rates measured for the oxidation of acrolein, propene, propane, and carbon monoxide and the rate of the water-gas-shift reaction. 
Please note that not all measured rates are initial rates, due to the fact that the conversion was too high in case of acrolein and propene oxidation. In addition, acrolein oxidation was measured in dry feed. Therefore, the plot may illustrate simply differences in the order of magnitude of the different reaction rates. Acrolein oxidation is the fastest reaction, about ten times faster than propene oxidation and hundred times faster than propane oxidation. The slowest reactions are carbon monoxide oxidation and the water-gas-shift reaction, about one hundred times slower than propane oxidation.

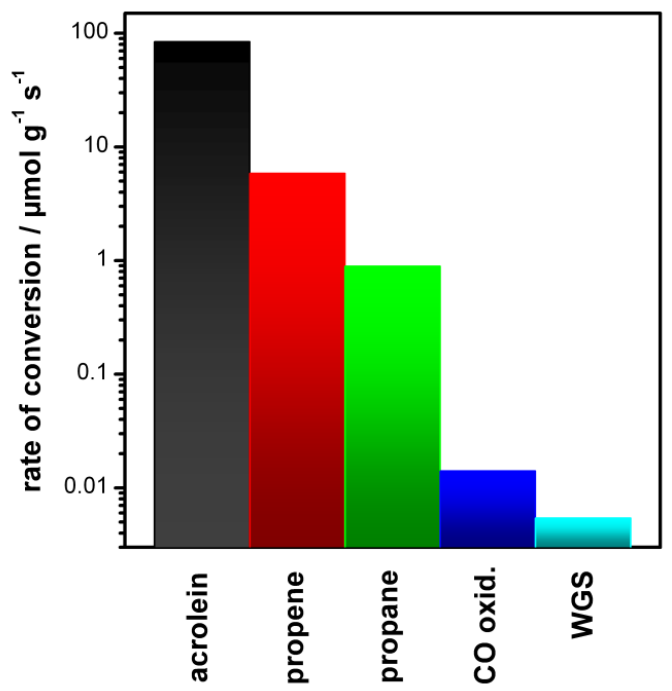

Figure 18. Comparison of propane, propylene, acrolein (top), propane, and CO oxidation and water gas shift activity (bottom) of the catalyst.

\section{Discussion}

\subsection{Catalyst stability and surface dynamics}

The most important requirement for any kinetic study is the overall steady state stability of the catalyst under reaction conditions. The analysis of catalytic data measured over a period of more than ten months under varying feed composition, temperature and contact times reveals that phase-pure M1 is absolutely stable over such a long term (Fig. 8). This is a very 
important finding not only with respect to the usability of the acquired kinetic data, but also in view of any potential industrial application of such a catalyst. There are only few remarks on time on stream behaviour and catalyst deactivation in the literature concerning $\mathrm{MoVTeNb}$ mixed oxide catalysts. Balcells et al. reported that the catalytic activity changes with time, especially when reaction conditions are changed.[11, 33] However, the catalyst used in that study was probably not phase-pure M1, but a mixture of the phases M1 and M2. Characterization results of the used catalysts were not shown. We suppose that phase purity is crucial for high stability. Admixtures of thermodynamically more stable mixed or binary phases like $\mathrm{M} 2$ or $\mathrm{MoO}_{3}$ may trigger re-crystallization or phase transformations under reaction conditions. Novakova et al. reported about modification of the crystalline structure during use of MoVSbNb oxide catalysts in propane oxidation.[34] The peaks belonging to ternary $\mathrm{MoV}$ and $\mathrm{MoNb}$ oxide phases in the XRD patterns of the fresh catalyst decrease at the expense of a relative increase in the intensity of peaks assigned to $\mathrm{MoO}_{3}$ in the used catalyst. Accordingly, the use of phase-pure M1 oxide in the current study has been proven to be beneficial. This becomes evident from the in-situ XRD experiment. The results clearly show that under typical as well as non-typical reaction conditions of propane oxidation the crystal structure of M1 is stable (Figs. 3-5). It is interesting that under strongly reducing conditions, i.e., in presence of propane only, the appearance of the primary catalyst particles is damaged, as visualized by electron microscopy (Figs. 6-7), but that the damaged material is still M1 from a crystallographic point of view (Fig. 4d) though showing significantly changed cell constants (Fig. 3). One possible explanation for the observed expansion of the $a b$ plane could be the loss of Te by preferential reduction. Te is hosted in the hexagonal voids of the $a b$ plane and may contribute to a stabilization of the M1 structure.[35, 36] This is in agreement with the EDX analysis that reveals a loss of tellurium. 
In summary, as long as strongly reducing conditions, i.e., a regime of total oxygen consumption, are avoided, the M1 crystal structure remains unaffected and chemical changes of the bulk are also not observed as it becomes clear from the constant lattice parameters observed during the in-situ XRD experiments (steps 3-10 in Fig. 3). This is of particular interest, as it is known that the structure of the M1 surface dynamically changes with changes in the reaction conditions. $[30,37]$ These changes are restricted to a thin surface layer in nmdimensions (Fig. 2) and are observable by synchrotron-based near-ambient-pressure X-ray photoelectron spectroscopy (NAP-XPS) applying a constant kinetic energy of the photoelectrons of $150 \mathrm{eV}$ (Figs. 1-2). The majority of electrons analysed under these conditions are released within a depth of approximately $0.6 \mathrm{~nm}$. The integral measurement of the catalyst powder probes, therefore, not much more than a single layer of the M1 unit cell $(a \times b \times c=2.1 \times 2.7 \times 0.4 \mathrm{~nm})$ in $c$ direction or only a part of the unit cell in $a$ and $b$ direction, respectively. By switching from dry to wet feed (total pressure in the NAP-XPS experiment is $25 \mathrm{~Pa}$ ), the surface of $\mathrm{M} 1$ is enriched in $\mathrm{V}$ and Te mainly at the expense of Mo. Moreover, the fraction of $\mathrm{V}$ in the highest oxidation state 5+ increases significantly (Fig. 1). The surface concentration of $\mathrm{V}^{5+}$ correlates with the abundance of acrylic acid detected by mass spectrometry in the effluent gas of the in-situ XPS cell.[30] These surface changes are reversible (Fig. 1) and highlight in conjunction with the stability of the crystalline bulk the unique ability of the M1 phase to adopt the surface structure in response to the chemical potential of the substrate molecule, which is essential for an oxidation catalyst that catalyses the transformation of an alkane molecule into a highly functionalized product, like acrylic acid. The fact that the kinetics of these surface changes appear slowly compared to the kinetics of the organic reaction indicate that the surface layer is strongly coupled to the bulk crystal structure by chemical bonds. This would explain the impact of composition, 
crystallinity, and phase-purity of the bulk on the catalytic properties of M1 MoVTeNb oxide catalysts in propane oxidation.

The dynamic surface changes have to be considered in the discussion of the kinetic data acquired by applying varying temperature, oxygen partial pressure, and steam content. Intrinsically, heterogeneous catalysis is a highly dynamic phenomenon, since the substrate molecules in general undergo chemical interactions with the catalyst surface and the adsorption complex is subjected to electronic and structural modifications in the course of the catalytic cycle. Catalyst stability in the stationary state requires, therefore, a flexible structural matrix in which the active ensemble is embedded. In direct oxidation of propane to acrylic acid that involves hydrogen abstraction and oxygen insertion perhaps on different sites, the catalyst requirements are particularly challenging. The dynamic response of the surface composition towards temperature and feed composition indicates that a correlation of catalytic properties with the crystal structure and chemical composition of the bulk is misleading and implies that the nature of the active sites and, hence, the reaction pathway may change with the reaction conditions. In other words, the boundary condition of a structurally defined single active site is definitely not applicable in case of M1 as a catalyst for oxidation of propane, and perhaps, also not in case of other mixed oxide catalysts for selective oxidation in general. The implications of these considerations on the outline of a reaction network of propane oxidation over M1 catalysts will be discussed in the following sections.

\subsection{Reaction network in propane oxidation}

The variation of reaction conditions of propane oxidation over phase-pure M1 disclosed new aspects, which are unique to $\mathrm{MoVTeNb}$ oxide composed exclusively of the M1 phase. In 
addition, some findings are similar to results observed in studies, in which phase mixtures of MoVTeNb oxides have been used. The most important observations are listed below:

(i) The presence of steam is beneficial for acrylic acid synthesis, which is in agreement with previous literature reports. $[3,11,38-40]$

(ii) Propane conversion increases with increasing oxygen : propane ratio, but the selectivity is hardly influenced by the oxygen partial pressure.

(iii) The apparent activation energy of propane consumption at low conversions strongly depends on the feed composition.

(iv) Formation of acetic acid is not observed in dry feed.

(v) M1 does not catalyze CO oxidation.

(vi) The formation of $\mathrm{CO}$ and $\mathrm{CO}_{2}$ follow different trends and therefore the two products have not the same origin and cannot be summarized as $\mathrm{CO}_{\mathrm{x}}$ in kinetic considerations.

\subsubsection{Pathways to products of selective oxidation}

At very short contact time or low conversion (Fig. 10), propene occurs with high selectivity, which is in line with the view of propene as stable reaction intermediate that undergoes consecutive transformations after re-adsorption. This is in agreement with studies of phasepure M1 catalysts by Ueda et al.[17, 41, 42] It is generally accepted that propane activation over vanadium oxide based catalysts happens via the formation of an isopropyl radical mediated by vanadyl oxygen atoms.[43-45] The formation of this radical by breaking the first $\mathrm{C}-\mathrm{H}$ bond in the methylene group of propane is the rate-determining step.[43] The propyl radical can rebind to the surface forming surface alkoxy species as key surface reaction intermediates. The abstraction of the second hydrogen atom from the alkoxy intermediate or from isopropyl radicals in the gas phase result in propene, whereas different specific pathways 
are possible for the second step, which, however, can hardly be distinguished from an energetic point of view.[43] The fact that the selectivity to propene is only at the shortest contact times high and reaches already at a conversion of $\mathrm{X}=0.1$ a value of only 0.3 indicates that under propane oxidation conditions, propene oxidation is much faster than propane oxidation. This is also supported by the propene oxidation experiments over M1 (Figs. 15a, 18). However, the corresponding rate (Fig. 18) cannot be directly compared to the conversion of propene under propane oxidation conditions, as the surface composition of M1 and thus catalytically active sites are influenced by the redox potential of the gas phase.[37]

Another intermediate postulated by Bettahar et al. is acrolein as the product of the allylic oxidation of propene.[4] Without any doubt, acrolein can be oxidized to acrylic acid in a very fast and very selective reaction (Fig. 16). The oxidation of acrolein is by an order of magnitude faster than the oxidation of propene (Fig. 18). Here, the same restrictions with respect to the state of the M1 surface under conditions of acrolein oxidation exist as discussed above for propene. In spite of this uncertainty, the fact that no acrolein was detected in the gas phase during propene or propane oxidation (Figs. 9, 10,15) does not mean that it is not formed as intermediate product, but it can be speculated that at the high temperatures investigated the oxidation of acrolein occurs faster than the desorption.

Auxiliary propene added to the feed gas of propane oxidation in small amounts is fully converted without lowering the propane consumption rate (Fig. 15b). The added propene is mainly converted to acrylic acid. This result is in good agreement with the hypothesis of two structurally coupled active sites of which one is responsible for oxidative dehydrogenation of propane to propene, while the second is responsible for further oxidation of propene. Such a mechanism has been suggested in case of $\mathrm{MoVTeNb}$ oxide catalysts composed of phase mixtures.[14, 46-51] Here, consecutive oxidation of propene may, however, also occur over secondary phases. These considerations resulted in the postulation of the phase cooperation 
concept.[51] Accordingly, high activity has been attributed to a synergistic effect between the MoVTe oxide phases M1 and M2, M1 being responsible for oxidative dehydrogenation of propane, while the M2 phase assists the M1 phase in propene oxidation to acrylic acid at high conversion.[48, 52] Our propene addition experiments over phase-pure M1 imply that phase cooperation is not an indispensable requirement for high catalyst performance. The observation that the propane consumption rate is not influenced by addition of propene can be rationalized by the fact that the oxidation of propene is much faster than the consumption of propane, by an order of magnitude (Fig. 18). Another argument for a consecutive pathway is the finding that acrylic acid clearly appears to be a secondary product (Figs. 9, 10).

\subsubsection{Pathways to products of deeper oxidation}

The undesired products of deeper oxidation observed in the present study are acetic acid, carbon monoxide, and carbon dioxide.

The formation of acetic acid has been discussed to occur on this type of catalysts either via degradation of acrylic acid[17] or via formation of acetone from propene.[7, 8] Acetone can be formed over M1, but only on the more reduced M1 surface under propene oxidation conditions in wet feed, i.e., at higher abundance of weakly acidic $\mathrm{OH}$ groups on the catalyst surface that may favour the acid-catalyzed transformation of propene via isopropanol as intermediate into acetone. But acetone is stable against total oxidation (Fig. 15 a), and no correlation between formation of acetone and formation of acetic acid could be observed during the propene oxidation experiments. No acetone was found during oxidation of propane (see Fig. 9), even not when propene was added to the feed (Fig. 15 b). Therefore, based on these observations the fact that the formation of acetic acid starts when the selectivity to acrylic acid reaches its maximum we postulate that acetic acid is exclusively formed by oxidative degradation of acrylic acid. A possible route would be the decomposition of acrylic 
acid into carbon dioxide and ethene (Eq. 4). Especially, as a small amount of ethene was formed during propane oxidation, although the amount was so small that it was not included into selectivity calculations ( $\mathrm{S}<<0.01$ ). Decomposition may be followed by carbon dioxide desorption while ethene mainly stays adsorbed or is re-adsorbed and directly further oxidized (Eq. 5). It is well known for decades that oxide catalysts containing Mo and $\mathrm{V}$ are very suitable for the oxidation of ethane via ethene to acetic acid.[53-58] In contrast, in studies investigating the partial oxidation of ethane over M1 catalysts, acetic acid was found not at all or only in trace amounts.[59-62] However, in these studies the oxidation of ethane was carried out only in absence of steam. In at least two studies the authors mention that the presence of steam is beneficial for the formation of acetic acid from ethane.[61, 62] The complete absence of acetic acid in the product mixture in dry feed support the route for acetic acid formation via decomposition of acrylic acid in the presence of steam in the feed.

$$
\begin{aligned}
& \mathrm{CH}_{2}=\mathrm{CH}-\mathrm{COOH} \rightarrow \mathrm{CH}_{2}=\mathrm{CH}_{2}+\mathrm{CO}_{2} \\
& \mathrm{CH}_{2}=\mathrm{CH}_{2}+\mathrm{O}_{2} \rightarrow \mathrm{CH}_{3} \mathrm{COOH}
\end{aligned}
$$

Acetic acid could be a precursor for further oxidation to $\mathrm{CO}_{2}$ and formic acid (Eq. 6), which is under reaction conditions immediately decomposed to $\mathrm{CO}$ and $\mathrm{H}_{2} \mathrm{O}$ (Eq. 7).

$$
\begin{aligned}
& 2 \mathrm{CH}_{3} \mathrm{COOH}+3 \mathrm{O}_{2} \rightarrow 2 \mathrm{HCOOH}+2 \mathrm{CO}_{2}+2 \mathrm{H}_{2} \mathrm{O} \\
& \mathrm{HCOOH} \rightarrow \mathrm{CO}+\mathrm{H}_{2} \mathrm{O}
\end{aligned}
$$

Accordingly, it seems that acetic acid might be one major source of $\mathrm{CO}$ and $\mathrm{CO}_{2}$ at higher conversion. Acrolein oxidation results show that acrylic acid is thermally more stable against total oxidation than acetic acid (Fig. 16). The selectivity to acetic acid is strongly decreased with increasing temperature while the selectivity to acrylic acid is hardly influenced. Acrolein is not likely as a source of $\mathrm{CO}$, because in contrast to propane oxidation, the selectivity to carbon dioxide is higher than the selectivity to carbon monoxide in acrolein oxidation. 
Propene or its oxidation products seem to give also both carbon oxides as can be concluded from the propene addition experiment using two reactors connected in series (Fig. 15 b).

The two carbon oxides are often handled in the literature as one species denoted as $\mathrm{CO}_{\mathrm{x}}$. From the analysis of the general gradients in the three-dimensional experimental space in Fig. 12 it becomes evident that $\mathrm{CO}$ and $\mathrm{CO}_{2}$ are clearly formed via oxidation of several species. Degradation of acrylic acid via acetic acid should give $\mathrm{CO}_{2}$ in excess. In contrast, $\mathrm{CO}$ is under all conditions the more abundant carbon oxide, but with increasing contact time the fraction of $\mathrm{CO}_{2}$ increases, whereas a $\mathrm{S}_{\mathrm{CO} 2} / \mathrm{S}_{\mathrm{CO}}$ ratio of 1 is never surpassed within the range of explored reaction conditions. This indicates that other pathways of deeper oxidation occur that mainly result in $\mathrm{CO}$ as final product. The analysis of selectivity as a function of conversion in Fig. 10 gives some indication that $\mathrm{CO}$ could be a primary product formed directly from the alkoxide surface intermediate without desorption of any intermediate with an initial selectivity of about 0.015 at $\mathrm{X}=0$. This only applies under wet conditions, i.e., when steam is added to the feed. In contrast, $\mathrm{CO}_{2}$ is definitely a secondary product under all reaction conditions.

The changes in the $\mathrm{CO}_{2} / \mathrm{CO}$ ratio do not originate from $\mathrm{CO}$ oxidation, because carbon monoxide is a stable final product of oxidation. MoVTeNb oxide composed of the M1 structure performs hardly as catalyst for CO oxidation or the water gas shift reaction (Fig. 17). $\mathrm{CO}$ oxidation has been proven to proceed via a Langmuir-Hinshelwood mechanism that requires the simultaneous adsorption of $\mathrm{CO}$ and electrophilic oxygen species at the surface of the catalyst.[63] Oxygen activation seems to be a rather facile process on M1,[64] which keeps the average oxidation state of the surface metal ions at a high level and the concentration of electrophilic oxygen species as well as the abundance of coordinatively unsaturated $\mathrm{CO}$ adsorption sites low under stationary conditions of propane oxidation. The observation that $\mathrm{CO}$ behaves like an inert gas when co-fed to the propane oxidation feed is in 
agreement with the high oxidation state of the metals at the surface found by in-situ NAPXPS (Fig. 1b)[30] and proves the low concentration of electrophilic oxygen species, which is favourable to the acrylic acid selectivity.

\subsection{Kinetic parameters in the field of explored reaction conditions}

Fast oxygen activation is in accordance with an overall reaction order with respect to oxygen that is nearly zero, but always slightly positive (average value about 0.12 , Fig. $14 \mathrm{~b}$ ). The result is in good agreement with the literature.[42] Interestingly, higher oxygen content in the feed increases the yield of acrylic acid via an increase in conversion, but without affecting the selectivity. In the literature, it is generally assumed that only completely reduced, nucleophilic oxygen $\left(\mathrm{O}^{2-}\right)$ as a part of a metal oxide surface species is involved in the transformation of an alkane into products of selective oxidation. This is definitely true when the conversion of an alkane is performed in absence of gas phase oxygen and accompanied by reduction of the oxide. Some kinetic experiments in the oxidation of olefins support the idea that nucleophilic oxygen is involved in the selective insertion of oxygen into the hydrocarbon skeletal and the formation of valuable oxygenates, while electrophilic oxygen species are responsible for nonselective oxidation of the hydrocarbon molecule to carbon oxides.[15] In contrast, in-situ photoelectron spectroscopy in combination with product analysis clearly show that ethylene oxide is formed on the surface of silver catalysts involving electrophilic oxygen species, while nucleophilic oxygen is responsible for ethylene combustion.[65] Due to experimental difficulties in case of oxidative alkane transformations over metal oxides, the question concerning the nature of the beneficial oxygen species has not yet been answered convincingly and, therefore, it is not clear whether insertion of nucleophilic oxygen is the exclusive pathway to products of selective oxidation in the presence of the hydrocarbonoxygen feed mixture. The oxygen content in the feed has clearly an effect on the apparent 
activation energy in our study that means that oxygen species affect the reaction network somehow, either via the nature of the M1 surface or via reaction intermediates. The oxygen addition experiments (Fig. 13 c) clearly indicate a deficit in oxygen on the surface of M1 under stationary conditions. Since the addition of oxygen increases the conversion of propane, but does not affect the selectivity to acrylic acid, the added oxygen probably causes an increase in the average oxidation state of the catalyst surface, which leads to an increase of the number of active sites for propane activation and, consequently, in an increased conversion. The added oxygen will probably increase the pool of alkoxide species available for consecutive reactions on the surface under stationary conditions. This clearly implies the potential of reaction engineering and process design for improvements in the yield of acrylic acid.

The influence of the steam content on the overall activation energy is even higher, compared to the influence of oxygen. Especially the absence of steam has a large impact on conversion, selectivity, and the overall activation energy for propane consumption. In dry feed, the conversion is decreased and total oxidation of acrylic acid is increased, compared to wet feed.

The overall activation energies for propane consumption are in the range of $80-95 \mathrm{~kJ} \mathrm{~mol}^{-1}$ under dry reaction conditions, and are lowered to $55-75 \mathrm{~kJ} \mathrm{~mol}^{-1}$ under wet conditions. The values obtained for wet conditions are in good agreement with the value of $65.4 \mathrm{~kJ} \mathrm{~mol}^{-1}$ given by Ueda et al.[13] and the value of $60 \mathrm{~kJ} \mathrm{~mol}^{-1}$ used by Balcells et al. for simulation of kinetic measurements.[11] The value obtained under dry conditions cannot be directly compared to literature data, but Mitra et al. reported very similar values $\left(78-90 \mathrm{~kJ} \mathrm{~mol}^{-1}\right)$ for the oxidative dehydrogenation of propane using supported vanadia catalysts.[66] It has been speculated in the literature that steam blocks unselective catalytic sites by adsorption.[4] This would explain the enhanced selectivity to acrylic acid, but not the enhanced conversion of propane. Therefore, it seems more likely that steam influences the selective catalytic sites, 
either their nature or just their number. The fact that steam has a large influence on the overall activation energy of propane consumption indicates that rather the nature than the number of active sites is changed, which is again in agreement with the in-situ NAP-XPS findings (Figs. 1-2). A mere increase of the number of active sites would increase reaction rates but not the activation energy. The assumption of a constant number of active sites is also in agreement with propane adsorption measured by microcalorimety.[30] The number of adsorption sites for propane was the same in the state before and after reaction, respectively, while the heat of adsorption was considerably lower after reaction.

\subsection{Reaction network and structure-function correlation}

From the large data set of kinetic observations presented here it was possible to derive a reaction scheme without having to assume any quantitative description of the reaction network by models (Scheme 1). The reaction network in propane oxidation on the surface of MoVTeNb oxide exclusively composed of the M1 phase appears evidently much simpler compared to networks that prevail over phase mixtures. In particular, the oxyhydration of readsorbed propene assisted by weak acid sites leading to $\mathrm{CO}$ and $\mathrm{CO}_{2}$ via iso-propanol, acetone, and acetic acid does not occur in competition to the allylic oxidation.

The first key surface intermediate is an isopropyl alkoxide species, which is transformed into propene by abstraction of the second hydrogen atom. The $\mathrm{CO}$ formation may occur from decomposition of the alkoxide intermediate. This is a minor reaction pathway in competition to selective oxidation of the alkoxide intermediate as seen from the weak abundance of primary $\mathrm{CO}$ in contrast to the clearly secondary product $\mathrm{CO}_{2}$ arising from decarboxylation of $\mathrm{C} 3$ and $\mathrm{C} 2$ carboxylic acids.

It was not possible under the present set of conditions to reach the maximum performance of the M1 catalyst. However, it was established that a crucial condition in operating the catalyst 
at high load is to never fully convert oxygen as then irreversible damage of the catalyst destroys its performance. This observation supports the necessary but not sufficient function of the M1 bulk structure for catalytic performance of propane oxidation.

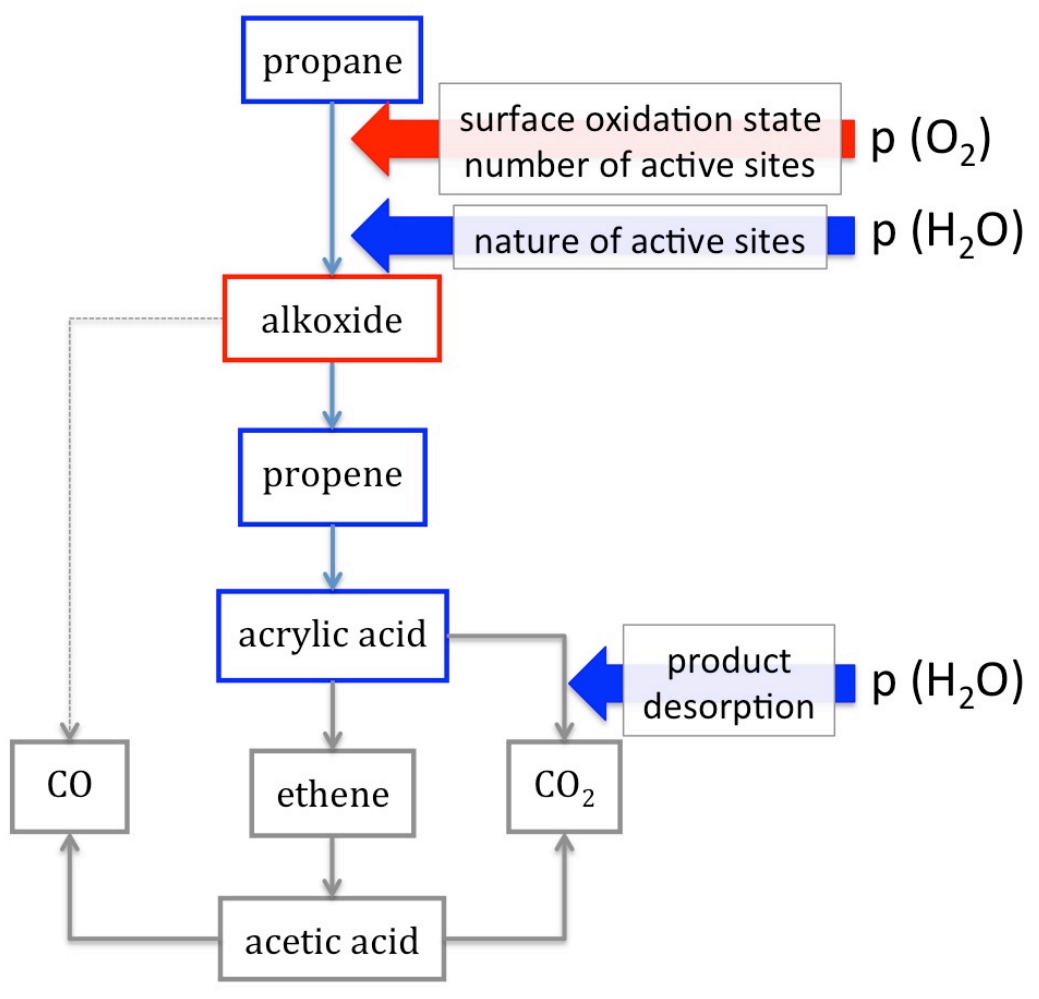

Scheme 1. Proposed reaction network of propane oxidation over phase-pure M1 MoVTeNb oxide including an alkoxide as the key surface intermediate (red) and all reaction intermediates detectable by gas chromatography. The oxygen partial pressure determines the number of active sites for propane activation by controlling the oxidation state of the catalyst surface. The nature of the active sites is changed dynamically governed by the chemical potential of the gas phase, in particular by auxiliary steam. Water facilitates acrylic acid desorption, but opens also undesired reaction pathways, like a minor route from the alkoxide intermediate to $\mathrm{CO}$ and the oxidation of ethene to acetic acid.

An increase in the partial pressure of oxygen keeps the catalyst surface under stationary conditions in a high oxidation state and increases the number of active sites for propane activation und thus the propane conversion. Excess oxygen does not deteriorate the selectivity showing that the chemical potential of oxygen does not directly control deep oxidation. One function of the thin active layer is thus to act as "oxygen buffer". This can be realized by a 
structural flexibility allowing for interchange between bridging and terminal oxygen groups according to the gas phase chemical potential. Such a site may be envisaged as a molecular structure similar to a poly vanadate. A suitable topology would be a cage structure allowing loosing several V-O-V bonds without breaking apart. The structure is formed and stabilized in the presence of steam. Such a view would support the critical relevance of water found in the kinetic data of this study exceeding the supporting function for acid desorption.

This picture is equivalent of defining the active system as semiconductor with an "adsorbate" as active site and electron sources and sinks represented by the reactants and the bulk, respectively. The resulting band structure may be quite complex as several adsorption sites are possible (e.g., the V-enriched sites and the Mo-enriched sites). If the charge carrier transport scheme is known and the energetic positions of the interfaces can be determined then the reaction can be cast in a semiconductor band scheme allowing a quantitative energetic description more adequate than assigning formal oxidation states to isolated atoms although much speaks for a covalently bonded molecular feature as active site. In this picture the specific electronic structure of the supporting M1 will become an important factor allowing to reconcile that not every support of a polymeric V structure can act as selective oxidation catalyst.

\section{Conclusions}

Phase purity and catalyst homogeneity ensure high stability of MoVTeNb oxide in selective oxidation of propane to acrylic acid. The catalyst is considered as a self-supporting system bearing an active monolayer under reaction conditions that is chemically different from the bulk and responses dynamically to the chemical potential of the feed, in particular to the steam content. 
Phase purity of the catalyst reduces the complexity of the reaction network in propane oxidation resulting in improved selectivity to the desired oxygenate acrylic acid. The initial formation of propene via an alkoxy surface species followed by its consecutive allylic oxidation directly to acrylic acid without desorption of intermediates is the dominating reaction route.

Increasing the oxygen partial pressure in the feed has a positive impact on activity by increasing the number of active $\mathrm{V}^{5+}$ sites without negative implications on selectivity.

The selectivity is in particular restricted by degradation of acrylic acid at higher conversion into $\mathrm{CO}_{2}$ and ethene, which is further oxidized via acetic acid to $\mathrm{CO}$ and $\mathrm{CO}_{2}$. While the decomposition of acrylic acid is suppressed in wet feed, auxiliary steam may also act detrimental by establishing a new, unselective pathway from the alkoxy intermediate directly to $\mathrm{CO}$, which is, however, of minor importance. $\mathrm{CO}$ oxidation and the water-gas shift reaction including gaseous $\mathrm{CO}$ can be excluded from the reaction network.

Water and oxygen both fulfill besides functions as reactants critical roles in establishing and stabilizing the reactive termination structure. If the emerging picture of the chemical dynamics can be complemented with a picture of the relevant charge carrier dynamics then it may be possible to construct a concept of the active site detailed enough that modern theoretical methods may derive a mode of operation. Using the parent bulk structure of M1 for such purposes falls short of explaining the kinetic observations reported in this work.

\section{Acknowledgements}

The authors are grateful to Dr. Yury V. Kolen'ko and Dr. Maricruz Sanchez Sanchez for preparation of the catalysts. We thank Maike Hashagen and Gisela Lorenz for surface area determination, Gisela Weinberg and Dr. Wei Zhang for EDX analysis, and Edith Kitzelmann for assistance in the XRD measurements. The HZB staff is acknowledged for their continual 
support of the high-pressure electron spectroscopy activities of the FHI at BESSY II. We also thank the Südchemie AG (meanewhile Clariant Produkte (Deutschland) $\mathrm{GmbH}$ ) for financial support and Dr. Gerhard Mestl (Clariant Produkte (Deutschland) $\mathrm{GmbH}$ ) for scientific discussions.

\section{References}

[1] G. Centi, F. Cavani, F. Trifiro, Chapter 8: New aspects of the mechanisms of selective oxidation and structure/activity relationships, in: Selective Oxidation by Heterogeneous Catalysis, Kluwer Academic, New York, Boston, Dordrecht, London, Moscow, 2001, pp. 363-495.

[2] R. Schlögl, Topics in Catalysis, 54 (2011) 627-638.

[3] R. Fushimi, S.O. Shekhtman, A. Gaffney, S. Han, G.S. Yablonsky, J.T. Gleaves, Industrial \& Engineering Chemistry Research, 44 (2005) 6310-6319.

[4] M.M. Bettahar, G. Costentin, L. Savary, J.C. Lavalley, Applied Catalysis, A: General, 145 (1996) 1-48.

[5] R.K. Grasselli, Catalysis Today, 99 (2005) 23-31.

[6] A. Trunschke, Propane selective oxidation to acrylic acid, in: C. Hess, R. Schlögl (Eds.) Nanostructured Catalysts: Selective Oxidation Reactions, RSC Nanoscience \& Nanotechnology, Cambridge, 2011, pp. 56-95.

[7] P. Botella, J.M. Lopez Nieto, B. Solsona, A. Mifsud, F. Marquez, Journal of Catalysis, 209 (2002) 445-455.

[8] L. Luo, J.A. Labinger, M.E. Davis, Journal of Catalysis, 200 (2001) 222-231.

[9] M. Lin, T.B. Desai, F.W. Kaiser, P.D. Klugherz, Catalysis Today, 61 (2000) 223 229.

[10] J.-M.M. Millet, Topics in Catalysis, 38 (2006) 83-92.

[11] E. Balcells, F. Borgmeier, I. Grisstede, H.G. Lintz, F. Rosowski, Applied Catalysis, A: General, 266 (2004) 211-221.

[12] F. Naraschewski, A. Jentys, J. Lercher, Topics in Catalysis, 54 (2011) 639-649.

[13] W. Ueda, D. Vitry, T. Katou, Catalysis Today, 99 (2005) 43-49.

[14] R.K. Grasselli, D.J. Buttrey, J.D. Burrington, A. Andersson, J. Holmberg, W. Ueda, J. Kubo, C.G. Lugmair, A.F. Volpe, Jr., Topics in Catalysis, 38 (2006) 7-16.

[15] J. Haber, W. Turek, Journal of Catalysis, 190 (2000) 320-326.

[16] J. Haber, E. Lalik, Catalysis Today, 33 (1997) 119-137.

[17] D. Vitry, Y. Morikawa, J.L. Dubois, W. Ueda, Applied Catalysis, A: General, 251 (2003) 411-424.

[18] R. Naumann d'Alnoncourt, Y.V. Kolen'ko, R. Schlögl, A. Trunschke, Combinatorial Chemistry and High Throughput Screening, 15 (2012) 161-169.

[19] P. Botella, E. Garcia-Gonzalez, A. Dejoz, J.M. Lopez Nieto, M.I. Vazquez, J. Gonzalez-Calbet, Journal of Catalysis, 232 (2005) 246.

[20] Y.V. Kolen'ko, W. Zhang, R.N. d'Alnoncourt, F. Girgsdies, T.W. Hansen, T. Wolfram, R. Schlögl, A. Trunschke, ChemCatChem, 3 (2011) 1597-1606.

[21] T. Ushikubo, K. Oshima, A. Kayou, M. Hatano, Ammoxidation of propane over Mo-V-Nb-Te mixed oxide catalysts, in: Studies in Surface Science and Catalysis, Elsevier, 1997, pp. 473-480. 
[22] M. Baca, J.-M.M. Millet, Applied Catalysis A: General, 279 (2005) 67-77.

[23] P. DeSanto, Jr., D.J. Buttrey, R.K. Grasselli, C.G. Lugmair, A.F. Volpe, Jr., B.H. Toby, T. Vogt, Zeitschrift fuer Kristallographie, 219 (2004) 152-165.

[24] D. Balzar, Voigt-Function Model in Diffraction Line-Broadening Analysis, in:

R.L. Snyder, H.J. Bunge, J. Fiala (Eds.) Defect and Microstructure Analysis from Diffraction, Oxford University Press, New York, 1999, pp. 94-126.

[25] K.S.W. Sing, Pure and Applied Chemistry, 57 (1985) 603-619.

[26] H. Bluhm, M. Hävecker, A. Knop-Gericke, M. Kiskinova, R. Schlögl, M. Salmeron, MRS Bulletin, 32 (2007) 1022-1030.

[27] M. Salmeron, R. Schlögl, Surface Science Reports, 63 (2008) 169-199.

[28] E.M. Vass, M. Hävecker, S. Zafeiratos, D. Teschner, A. Knop-Gericke, R. Schlögl, Journal of Physics: Condensed Matter, 20 (2008) 184016.

[29] A. KnopGericke, E. Kleimenov, M. Hävecker, R. Blume, D. Teschner, S. Zafeiratos, R. Schlögl, V.I. Bukhtiyarov, V.V. Kaichev, I.P. Prosvirin, A.I. Nizovskii, H. Bluhm, A. Barinov, P. Dudin, M. Kiskinova, Chapter 4: X-Ray Photoelectron Spectroscopy for Investigation of Heterogeneous Catalytic Processes, in: C.G. Bruce, K. Helmut (Eds.) Advances in Catalysis, Academic Press, 2009, pp. 213-272.

[30] M. Hävecker, S. Wrabetz, J. Kröhnert, L.-I. Csepei, R. Naumann d'Alnoncourt, Y.V. Kolen'ko, F. Girgsdies, R. Schlögl, A. Trunschke, Journal of Catalysis, 285 (2012) 48-60.

[31] S. Tanuma, C.J. Powell, D.R. Penn, Surface and Interface Analysis, 21 (1994) $165-176$.

[32] J.J. Yeh, I. Lindau, Atomic Data and Nuclear Data Tables, 32 (1985) 1-155.

[33] E. Balcells, F. Borgmeier, I. Grisstede, H.G. Lintz, Catalysis Letters, 87 (2003) 195-199.

[34] E.K. Novakova, E.G. Derouane, J.C. Vedrine, Catalysis Letters, 83 (2002) 177 182.

[35] P. Beato, A. Blume, F. Girgsdies, R.E. Jentoft, R. Schlögl, O. Timpe, A. Trunschke, G. Weinberg, Q. Basher, F.A. Hamid, S.B.A. Hamid, E. Omar, L. Mohd Salim, Applied Catalysis, A: General, 307 (2006) 137-147.

[36] D. Vitry, J.L. Dubois, W. Ueda, Journal of Molecular Catalysis A-Chemical, $220(2004) 67-76$.

[37] A. Celaya Sanfiz, T.W. Hansen, D. Teschner, P. Schnörch, F. Girgsdies, A. Trunschke, R. Schlögl, M.H. Looi, S.B.A. Hamid, The Journal of Physical Chemistry C, 114 (2010) 1912-1921.

[38] V.V. Guliants, R. Bhandari, J.N. Al-Saeedi, V.K. Vasudevan, R.S. Soman, O. Guerrero-Perez, M.A. Banares, Applied Catalysis, A: General, 274 (2004) 123-132.

[39] V.H. Rane, U. Rodemerck, M. Baerns, Journal of Chemical Technology and Biotechnology, 81 (2006) 381-386.

[40] J.B. Wagner, O. Timpe, F.A. Hamid, A. Trunschke, U. Wild, D.S. Su, R.K. Widi, S.B.A. Hamid, R. Schlögl, Topics in Catalysis, 38 (2006) 51-58.

[41] K. Oshihara, T. Hisano, W. Ueda, Topics in Catalysis, 15 (2001) 153-160.

[42] D. Vitry, Y. Morikawa, J.L. Dubois, W. Ueda, Topics in Catalysis, 23 (2003) 47-53.

[43] X. Rozanska, R. Fortrie, J. Sauer, The Journal of Physical Chemistry C, 111 (2007) 6041-6050.

[44] G. Fu, X. Xu, X. Lu, H.L. Wan, Journal of Physical Chemistry B, 109 (2005) 6416-6421. 
[45] H. Fu, Z.-P. Liu, Z.-H. Li, W.-N. Wang, K.-N. Fan, Journal of the American Chemical Society, 128 (2006) 11114-11123.

[46] R.K. Grasselli, A. Andersson, D.J. Buttrey, J.D. Burrington, C.G. Lugmair, A.F. Volpe, The role of site isolation and phase cooperation in selective light paraffin (amm)oxidation catalysis, in: Abstracts of Papers, 228th ACS National Meeting, Philadelphia, PA, United States, August 22-26, 2004, pp. COLL-245.

[47] R.K. Grasselli, J.D. Burrington, D.J. Buttrey, P. De Santo, Jr., C.G. Lugmair, A.F. Volpe, Jr., T. Weingand, Topics in Catalysis, 23 (2003) 5-22.

[48] J. Holmberg, R.K. Grasselli, A. Andersson, Applied Catalysis, A: General, 270 (2004) 121-134.

[49] P. Korovchenko, N.R. Shiju, A.K. Dozier, U.M. Graham, M.O. Guerrero-Perez, V.V. Guliants, Topics in Catalysis, 50 (2008) 43-51.

[50] M. Baca, A. Pigamo, J.L. Dubois, J.M.M. Millet, Topics in Catalysis, 23 (2003) $39-46$.

[51] R.G. Teller, J.F. Brazdil, R.K. Grasselli, W. Yelon, Journal of the Chemical Society, Faraday Transactions 1: Physical Chemistry in Condensed Phases, 81 (1985) $1693-1704$.

[52] M. Baca, M. Aouine, J.L. Dubois, J.M.M. Millet, Journal of Catalysis, 233 (2005) 234-241.

[53] K. Ruth, R. Burch, R. Kieffer, Journal of Catalysis, 175 (1998) 27-39.

[54] W. Ueda, K. Oshihara, Applied Catalysis, A: General, 200 (2000) 135-143.

[55] D. Linke, D. Wolf, M. Baerns, O. Timpe, R. Schlögl, S. Zeyss, U. Dingerdissen, Journal of Catalysis, 205 (2002) 16-31.

[56] X. Li, E. Iglesia, Applied Catalysis A: General, 334 (2008) 339-347.

[57] T.Y. Kardash, L.M. Plyasova, V.M. Bondareva, T.V. Andrushkevich, L.S. Dovlitova, A.I. Ischenko, A.I. Nizovskii, A.V. Kalinkin, Applied Catalysis A: General, 375 (2010) 26-36.

[58] E.M. Thorsteinson, T.P. Wilson, F.G. Young, P.H. Kasai, Journal of Catalysis, 52 (1978) 116-132.

[59] J.M. Lopez Nieto, P. Botella, M.I. Vazquez, A. Dejoz, Chemical Communications (Cambridge, United Kingdom), (2002) 1906-1907.

[60] P. Botella, E. Garcia-Gonzalez, A. Dejoz, J.M. Lopez Nieto, M.I. Vazquez, J. Gonzalez-Calbet, Journal of Catalysis, 225 (2004) 428-438.

[61] P. Botella, A. Dejoz, M.C. Abello, M.I. Vazquez, L. Arrua, J.M. Lopez Nieto, Catalysis Today, 142 (2009) 272-277.

[62] T.T. Nguyen, M. Aouine, J.M.M. Millet, Catalysis Communications, 21 (2012) $22-26$

[63] H.-J. Freund, G. Meijer, M. Scheffler, R. Schlögl, M. Wolf, Angewandte Chemie International Edition, 50 (2011) 10064-10094.

[64] K. Amakawa, Y.V. Kolen'ko, A. Villa, M.E. Schuster, L.-I. Csepei, G. Weinberg, S. Wrabetz, R. Naumann d'Alnoncourt, F. Girgsdies, L. Prati, R. Schlögl, A. Trunschke, ACS Catalysis, (2013) 1103-1113.

[65] V.I. Bukhtiyarov, A.I. Nizovskii, H. Bluhm, M. Hävecker, E. Kleimenov, A. Knop-Gericke, R. Schlögl, Journal of Catalysis, 238 (2006) 260-269.

[66] B. Mitra, I.E. Wachs, G. Deo, Journal of Catalysis, 240 (2006) 151-159. 